Maurer School of Law: Indiana University

Digital Repository@Maurer Law

Indiana Law Journal

Volume 94 | Issue 4

Article 6

Fall 2019

\title{
Bitcoin: Order Without Law in the Digital Age
}

John O. McGinnis

Northwestern University, j-mcginnis@law.northwestern.edu

Kyle Roche

Boies Schiller Flexner LLP, kyle@rochefreedman.com

Follow this and additional works at: https://www.repository.law.indiana.edu/ilj

Part of the Commercial Law Commons, Contracts Commons, Government Contracts Commons, Law and Economics Commons, and the Law and Society Commons

\section{Recommended Citation}

McGinnis, John O. and Roche, Kyle (2019) "Bitcoin: Order Without Law in the Digital Age," Indiana Law Journal: Vol. 94 : Iss. 4 , Article 6.

Available at: https://www.repository.law.indiana.edu/ilj/vol94/iss4/6

This Article is brought to you for free and open access by the Law School Journals at Digital Repository @ Maurer Law. It has been accepted for inclusion in Indiana Law Journal by an authorized editor of Digital Repository @ Maurer Law. For more information, please contact rvaughan@indiana.edu.

\section{$\Psi$}

JEROME HALL LAW LIBRARY

INDIANA UNIVERSITY

Maurer School of Law
Bloomington 


\title{
Bitcoin: ORder Without LAW IN The Digital Age
}

\author{
JOHN O. MCGINNIS* \& KYLE ROCHE**
}

Modern law makes currency a creature of the state and ultimately the value of its currency depends on the public's trust in that state. While some nations are more capable than others at instilling public trust in the stability of their monetary institutions, it is nonetheless impossible for any legal system to make the precommitments necessary to completely isolate the governance of its money supply from political pressure. This proposition is true not only today, where nearly all government institutions manage their money supply in the form of central banking, but also true of past private banking regimes circulating their notes under the shadow of public law. However, bitcoin represents a potential third currency regime far more resistant to state control because it mints currency units that exist in no physical place, places a numerical ceiling on the number of units that can be created, and relies on scientific principles from cryptography to guarantee that ceiling and verify any person-to-person transfer. The trust required is not in any government but in the decentralized order of those who verify bitcoin transactions and those who create the software these verifiers choose to run on their connected computers.

This Article explores the fundamental structure of bitcoin, first by demystifying it as a technology, and second by showing how its decentralized order contrasts with other currency regimes. Unlike governments that use the power of law to compel action, bitcoin relies on a system of built-in incentives to encourage behavior that benefits not only those seeking to use bitcoin, but also bitcoin miners-those who voluntarily undertake the task of maintaining the payment network. While currently bitcoin is too volatile to compete with all but the worst government-issued currencies, the qualities of this system may give bitcoin a long-term advantage over many currencies. As the bitcoin ecosystem continues to grow, its nonlegal order can help it climb the rungs of stability created by distrust in government.

The technology underpinning bitcoin is the next point of innovation in the digital age - the same era that has already seen software create institutional disruption from Amazon, Facebook, and Uber, among many others. As bitcoin gains in popularity, it offers a platform for other kinds of technological alternatives to traditional legal regimes, like smart contracts. Bitcoin's order without currency law will facilitate other forms of order with less law.

This is a propitious time for fundamental examination of bitcoin. Despite experiencing significant speculation and volatility throughout late 2017 and early 2018, its ten-year history demonstrates a downward trend in volatility and an upward trend in market capitalization.

* George C. Dix Professor, Northwestern Pritzker School of Law. Thanks to Mark Movsesian, Nelson Lund, and participants at a Northwestern workshop.

** Associate, Boies Schiller Flexner LLP. I would like to thank my family for their support in my academic and professional pursuits - especially my late grandfather William J. Roche and grandmother Isabelle Grodem who I hope smile down while they read this. 


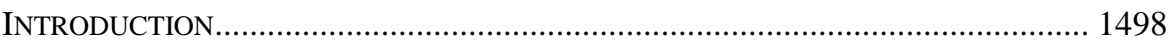

I. CURRENCIES UNDER PUBLIC AND PRIVATE LAW ………….............................. 1503

A. ORIgins OF Public LaW BANKING Through Central BanKS ...... 1504

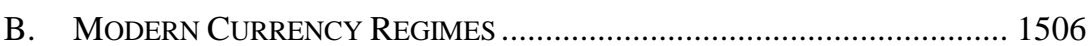

1. A THEORY OF MODERN CENTRAL BANKING............................. 1506

2. MONETARILY OPPRESSIVE REGIMES ....................................... 1508

3. THE EXAMPLE OF THE FED .................................................... 1509

C. THE EXPERIMENTS OF PRIVATE LAW BANKING ……........................... 1512

1. THE THEORY OF FREE BANKING …………………................. 1512

2. THE TERMINATION OF FREE BANKING ....................................... 1513

A. THE DisSOLUTION OF FreE B ANKING IN SCOTLAND.................. 1513

B. THE SUCCESSES AND REgUlatoRy OBSTACLES OF

FREE BANKING IN THE UNITED STATES .................................... 1514

II. BITCOIN AND THE IMPLICATIONS OF CURRENCY WITHOUT LAW .................. 1515

A. The INNOVATION OF DECENTRALIZED TRUST.................................... 1518

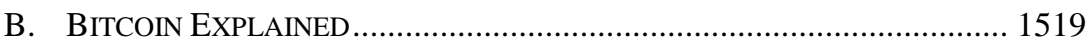

C. THE NONLEGAL ORDER OF BITCOIN ................................................... 1524

III. ADVANTAGES AND DISADVANTAGES OF BITCOIN ........................................ 1527

A. AdVANTAGES OF ORDER Without LAW IN CURRENCY ..................... 1527

1. COMPETITION TO STATE-ISSUED CURRENCIES .......................... 1527

2. ACCESS FOR THE UNDERBANKED .......................................... 1530

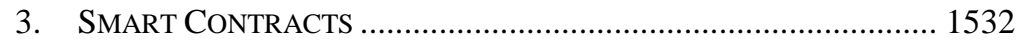

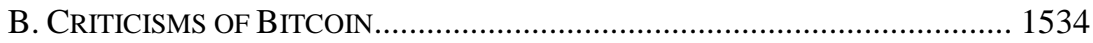

1. CRIME AND FRAUD IN BITCOIN ………………..................... 1535

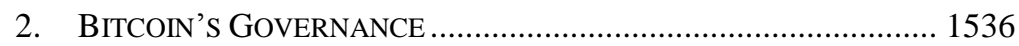

3. COMPETING CRYPTOCURRENCIES ……………....................... 1539

4. BITCOIN PRICE STABILITY ………………………………....... 1541

5. BITCOIN'S DEFLATIONARY MODEL........................................... 1543

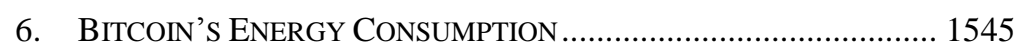

IV. BENCHMARKS FOR BITCOIN'S PRESENT AND FUTURE................................... 1546

A. CURRENCY RUNGS-A FRAMEWORK FOR ANALYZING BITCOIN'S

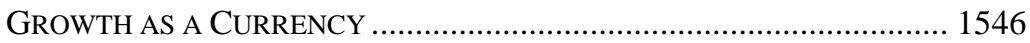

1. FIRST TIER: BITCOIN VS. RESERVE CURRENCIES....................... 1548

2. SECOND TIER: BITCOIN VS. EMERGING MARKET CURRENCIES . 1549

3. THIRD TIER: BITCOIN VS. GOLD (THE COMMODITY TIER) ......... 1551

4. FOURTH TIER: BITCOIN VS. OTHER CRYPTOCURRENCIES............ 1551

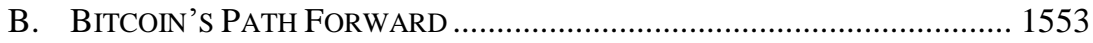

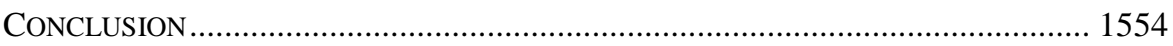

\section{INTRODUCTION}

Modern currency is a creature of law. In 1924, Georg Friedrich Knapp, the father of monetary theory, wrote that " $[t]$ he soul of currency is not in the material of the pieces, but in the legal ordinances which regulate their use." ${ }^{11}$ Knapp argued that

1. Georg Friedrich Knapp, The State Theory of Money 2 (1924). 
currency must be constituted by law since only governments can confer the requisite legitimacy to gain acceptance. ${ }^{2}$ Thus, the underlying value of a currency is intrinsically tied to the public's trust in that legal system.

Yet some citizens rightly have little trust in their legal system, particularly when it comes to currency. Nation-states can manipulate their currency, printing more money to fund projects for their favored supporters. The direct effects of such currency manipulation are felt most on its own people. Savings lose value as prices are driven up by inflation. ${ }^{3}$ Citizens become less certain of money as a store of value and economic growth suffers. ${ }^{4}$ Because currency is a creature of law, government control over money can be a form of oppression.

For instance, up until recent elections, ${ }^{5}$ Argentina has been historically such a monetarily oppressive regime. In fact, by the end of 2015, the Argentinian peso had become so devalued that major international corporations for a time stopped accepting transactions in the currency. ${ }^{6}$ And like many other such regimes, Argentina tried to prevent citizens from exiting to a better monetary regime by placing burdensome restrictions on the amount of U.S. dollars that can be purchased. ${ }^{7}$ The result is that citizens use black market exchanges despite the threat of prosecution. ${ }^{8}$

The recent advent of cryptocurrencies, bitcoin chief among them, poses both a practical challenge to monetarily oppressive regimes and a theoretical challenge to the view that the law of currency is the necessary foundation of currency. Bitcoin wallets are encrypted making seizure by government difficult. Bitcoin is minted by algorithm, not by any physical process that can be captured by agents of the state. Its use for payments depends on no physical entities, but instead on decentralized sources distributed over the internet. ${ }^{9}$ These sources update a public ledger, called the blockchain, which provides a complete history of all transactions.

The algorithm also limits the minting of new bitcoins, thus making it impossible to artificially inflate the currency. Ingeniously, the algorithm mints new bitcoins as a form of payment for those who verify the blockchain, called miners. Thus, it is the community of miners who ultimately execute the algorithm and update the

2. $I d$.

3. N. Gregory MankiW \& William Scarth, Macroeconomics 115 (2011).

4. K. Peren Arin \& Tolga Omay, Inflation and Growth: An Empirical Study of the Level and Variability Effects, in InFlation, FisCAl Policy AND CENTRAL BANKS 153, 159 (Leo N. Bartolotti ed., 2006).

5. In 2015, the new Argentinian President Mauricio Macri introduced drastic economic reforms, including the removal of certain currency controls. See Patrick Gillespie, Argentina's Economy Just Got a 7-Day Makeover, CNN: Bus. (Dec. 18, 2015, 10:42 AM), http://money.cnn.com/2015/12/18/news/economy/argentina-how-to-fix-an-economy [https:// perma.cc/R4T8-ZST2].

6. E.g., Patrick Gillespie, American Airlines No Longer Accepting Argentina's Peso, CNN: Bus. (Nov. 25, 2015, 2:56 PM), http://money.cnn.com/2015/11/25 /news/economy/american-airlines-stops-accepting-argentina-peso [https://perma.cc/E96K -N7JW].

7. Ken Parks, Argentina Moves to Limit Dollar Purchases, Wall ST. J. (Sept. 5, 2014, 4:35 PM), http://www.wsj.com/articles/argentina-moves-to-limit-dollar-purchases -1409949327 [https://perma.cc/HHK4-ADER].

8. Id.

9. For discussion of bitcoin, see infra Part II. 
blockchain. The soul of bitcoin is not the state, but a decentralized community with incentives to maintain the currency. Its essence is a form of order without law. ${ }^{10}$

Although the creation of bitcoin is impressive as a technological innovation, bitcoin's central innovation is in trust-the essential characteristic of any currency that will have long-term success. ${ }^{11}$ Bitcoin does not require faith in any public institution - such as the Federal Reserve, a monarch, or any other central authority - but rather trust in computer logic and the effects of a decentralized order that maintains it. ${ }^{12}$ Thus, bitcoin is nothing less than a fundamental assault on the idea that a law of currency is a necessary prerequisite of modern monetary order.

In fact, as this Article will show, bitcoin has the potential, even if that potential has not yet been substantially realized, to outperform the currencies produced by legal regimes as a store of value precisely because it requires no trust in a political process, but rather trust in a transparent set of rules. The regimes most susceptible to competition from bitcoin are the most monetarily oppressive ones because their citizens are most in need of an alternative to government-controlled currency. Bitcoin can also gain some market share because it may provide a cheaper form of payment system for the poor who cannot afford access to a bank, particularly those in less developed nations and those who want to send them remittances from abroad.

But as bitcoin gains more users by competing against monetarily oppressive regimes, it may even at some point become an alternative to more established regimes, and this opportunity is again a direct result of the law of currency. A legal system cannot generally make the precommitments necessary to completely isolate the governance of its money supply from all political pressure. ${ }^{13}$ This proposition is even true of regimes that depend on independent central banks that are the instruments of the state-even well-established ones, like the Federal Reserve.

To be sure, the U.S. dollar is the world's most trusted currency. ${ }^{14}$ Despite its many critics, the dollar has formed the basis for ninety percent of international trade

10. The hypothesis presented here draws on Robert Ellickson's theory that people largely govern themselves by means of informal rules-social norms - that develop without the aid of a state or other central coordinator. Robert C. Ellickson, ORder Without LAw: How Neighbors Settle Disputes (1994). Ellickson's theory of norms was derived in part by his close investigation of a variety of disputes arising from the damage created by escaped cattle in Shasta County, California. Id. at 3-4. Software enables humans to codify rules without government intervention, and the decentralized nature of bitcoin challenges many preconceived notions as to the necessary medium humans require to exchange value.

11. See, e.g., The Trust Machine, Economist (Oct. 31, 2015), https://www.economist.com/leaders/2015/10/31/the-trust-machine [https://perma.cc/WY58 -7UHR] (describing how the blockchain, the core technology underlying the bitcoin innovation, enables transactions between individuals who do not have an established trust relationship, in the absence of a third party). Part II of this Article explains what the blockchain is and how it functions.

12. See infra notes 126-30 and accompanying text.

13. This impossibility in the United States stems from the inability of legislatures to bind future legislatures. See John O. McGinnis \& Michael B. Rappaport, Symmetric Entrenchment: A Constitutional and Normative Theory, 89 VA. L. REV. 385, 388-89 (2003). Thus, legislation can change the structure of the Federal Reserve or its objectives.

14. John Waggoner, U.S. Dollar Is Still the World's Most Trusted Currency, USA ToDAY (Mar. 12, 2010, 8:41 PM), http://usatoday30.usatoday.com/money/economy/2010-03-12 
over the past thirty years because companies, consumers, and central banks around the world trust in the relative stability of the Federal Reserve and U.S. government. ${ }^{15}$ Yet the dollar is also a creature of law and has been subject to periods of severe and unexpected inflation. Thus, a cryptocurrency bitcoin has features that ultimately could lead it to gain more trust than the dollar enjoys.

If bitcoin succeeds as currency, it will do so by climbing rungs left open by law's frailties. It is already gaining some strength and stability by competing successfully against monetarily oppressive regimes and performing payment functions for the poor that bank regulations have made difficult. But as it gains stability, it becomes more competitive and climbs other open rungs because even the best currencies are subject to political risks built into the law of currency.

Thus, bitcoin is a story of creating order without currency law at the heart of the economy because it can serve people better than a more centralized order of currency law. It is thus of jurisprudential interest because order without law has never been of such potential importance. Order without law is not unknown to society. Social norms often regulate behavior without the benefit of formal law. Rules of etiquette tell people how to behave at the table without causing offense. Coordination rules help people walk down the street without bumping into one another. In a major work, Robert Ellickson showed that social norms, not law, governed responsibility in a community of cattle ranchers and farmers for the damage caused by cattle straying on the range. ${ }^{16}$

But while order without law is possible without software, software can improve on the enforcement of that order. The beauty of bitcoin's design is that its mechanism for enforcement can not only be more powerful than the informal mechanisms that enforce social norms but even more powerful in some respects than the formal mechanisms of law. A software algorithm is not subject to the problem of defection from nonlegal enforcement mechanisms. But it is also not subject to the risk of corruption in legal mechanisms of enforcement. To be sure, the blockchain's veracity is dependent on its distributed structure, but, as we will show, that structure is hard to corrupt because the community in charge of the software has strong incentives to maintain the value of the currency.

Insofar as bitcoin succeeds, the strength of its order will not be confined to currency. It will help other forms of order without other forms of law besides currency law become a more important part of commercial norms. The routes by which this new form of order without law will establish its empire are already becoming clear. If algorithms can direct when currency will be made available for payment and sensors can evaluate when those conditions for payment are met, algorithms will in some circumstances provide an alternative to contract law as well as currency law. ${ }^{17}$ Thus, while bitcoin is significant as a competitor to the law regulating currency, it also signals new forms of competition for other aspects of

-dollar12_CV_N.htm [https://perma.cc/TH79-8MKS].

15. Yalman Onaran, Dollar Dominance Intact as U.S. Fines on Banks Raise Ire, BLOOMBERG (July 16, 2014, 3:54 AM), http://www.bloomberg.com/news/articles/2014-07 -15/dollar-dominance-intact-as-u-s-fines-on-banks-raise-ire [https://perma.cc/5VLC-EJX2].

16. See ElLiCKSON, supra note 10, at 123.

17. For discussion, see infra Section III.A.3. 
commercial law. Bitcoin provides a code that, if successful, will generate ever more code to supplement and sometimes supplant the legal code.

Of course, law will not disappear. For instance, the general law of property and theft will continue to be necessary to protect those who entrust their bitcoins to bitcoin "hosted wallets"- service providers that manage individuals' bitcoins. ${ }^{18}$ But a successful bitcoin ecosystem would create a different mixture of nonlegal order and law.

This Article will examine the potential of bitcoin's order without currency law, contrasting it with legal regimes that have been previously the foundation of all currencies. Part I begins by tracing the historical evolution up to the advent of central banking. It then shows how modern central banks are creatures of the state. The worst of them are part of monetarily oppressive regimes in which citizens cannot trust their currency. But even the best, like the Federal Reserve, are subject to political pressure, reducing the trust citizens can repose in them. This Part ends by exploring the theory and historical practice of so-called free banking-an alternative to centralized banking whereby the money supply is governed by private law. But the private banking law regime's reliance on private law and brick-and-mortar institutions makes it readily subject to state regulation and indeed suppression. Thus, bitcoin represents a third modern currency regime, different from both central banks and free banking.

Part II of this Article explores the emergence of bitcoin as order without law in currency. This Part begins by putting bitcoin into perspective when compared with other groundbreaking technologies of the digital age. It then proceeds to explain how bitcoin functions - both from a technical and theoretical perspective- to demystify a technology that has oftentimes been misunderstood. Part II explains the two core bitcoin functionalities - encryption and the blockchain - that allow it to achieve a sophisticated nonlegal monetary order. It concludes by discussing the incentives to so-called miners - those who maintain the blockchain - to maintain the value of bitcoin. This Part also suggests that bitcoin is more resistant to state control than private currencies of old because it is encrypted and has no particular jurisdiction where it is created or resides. Bitcoin is also gaining strength as more people use it and institutions, like futures exchanges, grow up around it.

Having explored the strengths and weakness of fiat currencies in Part I, Part III aims to examine the benefits and costs of a monetary regime outside of state influence. It begins by examining why order without law in currency may offer greater liberty to individuals in their dealings with others, while also acting as a check against bad political actors. Bitcoin provides an alternative for citizens in monetarily oppressive regimes and for the many poor people, especially in the less developed world, who are unbanked. It shows that bitcoin will also facilitate smart contracts that will make payment intermediaries like banks superfluous and legal tender laws less necessary. Part III continues by addressing the many academic critiques of bitcoin's potential. It argues that bitcoin's first mover advantage will likely enable it to remain the cybercurrency of choice and that the incentives of miners will allow its software to be improved as necessary without endangering its core function and value.

18. For discussion of wallets and their problems, see infra Section III.B.1. 
Part IV provides a set of benchmarks for bitcoin's success and evaluates its current position against these benchmarks. The benchmarks are other kinds of currencies and gold, and the measures of success are volatility, value, and breadth of use. The highest tier of success for a currency is a reserve currency, like the U.S. dollar. Bitcoin is nowhere near that level of success. It is already less volatile and a better store of value than other cryptocurrencies.

We recognize that bitcoin is a moving target. Since we began this Article three years ago, bitcoin has moved from a niche interest of cryptocurrency enthusiasts to a phenomenon discussed almost daily in our leading newspapers. Thus, it is important to emphasize that our focus is not on predicting the price of bitcoin at any particular time, but on understanding the reasons that it is a unique innovation for storing value. Moreover, we recognize that the data presented in our graphs are merely snapshots in time that help illustrate our theories about its nature and prospects. They do not point to inevitable conclusions or destinations as the data will change in the future.

\section{Currencies Under Public and Private LaW}

When money is created by the rule of law, it inherits the same strengths and weaknesses of law. Legal regimes can create a framework of order for preserving the value of currency, thereby increasing users' trust. But law relating to currency has three possible weaknesses in creating and maintaining trust. First, it may have publicly stated objectives other than maintaining value. Modern central banks, for instance, sometimes shape the money supply to achieve other discretionary goals, like increasing employment. ${ }^{19}$ Second, the agents charged with carrying out the law may bend it to their own interests. Today, central banks may create an artificial economic boom to boost the prospects of the ruling party. ${ }^{20}$ Third, political actors may change the law: no precommitment can be ironclad in the world of politics. ${ }^{21}$

It is true that a stable framework for a currency is a great public good because it facilitates commerce and thus increases the wealth of a nation overall. But manipulating the currency can provide advantages to government leaders and political factions. And because so much is at stake in a currency, the forces for manipulation are sometimes strong enough to overwhelm those favoring the public good. Only by understanding the limits of currency law's effectiveness can we understand the promise of bitcoin, an innovation that reflects neither a public nor private law of currency. ${ }^{22}$

19. See infra Section I.B.1.

20. See discussion infra Section I.B.2.

21. See discussion infra Section I.C.1.

22. This Part begins its exploration of currency laws in the seventeenth century. However, the issues pertaining to the state creation of money begin much earlier. For example, in AD 301, Roman Emperor Diocletian issued the infamous Edictum de Pretiis Rerum Venalium, or the Edict on Maximum Prices. H. Michell, The Edict of Diocletian: A Study of Price Fixing in the Roman Empire, 13 CANAdian J. ECON. \& Pol. SCI. 1 (1947). As part of the Edict, Diocletian established maximum prices for the sale of goods, but continued to mass mint coins of low metallic value, further driving up inflation. Id. Because the Edict also set limits on wages, those who had fixed salaries found that their money was increasingly less valuable as 


\section{A. Origins of Public Law Banking Through Central Banks}

The Age of the Enlightenment dramatically transformed both the legal theory and practice behind social governance. ${ }^{23}$ And, while infrequently discussed, this change extended to the legal control of money. Precursors of modern central banking arose. John Locke, better known as the famous theorist of social contract, also provided theoretical justifications for the important but limited function of the law regulating currency - maintaining a stable value to facilitate commerce.

The Dutch were early innovators in moving toward more modern currency practices. The Bank of Amsterdam, established in 1609, is arguably the first precursor of a modern central bank. ${ }^{24}$ At the time, the currency of small states consisted in large part of the currencies of neighboring nations. ${ }^{25}$ The Bank of Amsterdam began accepting both foreign and local coinage at their market value, and after deducting a small management fee, credited its clients the remaining value in banknotes. ${ }^{26}$ Because the government guaranteed this credit, this removed much uncertainty from Dutch banknotes. ${ }^{27}$ This encouraged merchants to not only keep accounts with the bank, but also trade for goods with the debt owed to them by the banks. The banknotes issued by the Bank of Amsterdam were superior not only in convenience but in trust, as foreign coinage was often clipped and worn. ${ }^{28}$ Banknotes with their government guarantee, in contrast, were a more reliable store of value.

Since the international community at the time trusted its value, Dutch currency became greatly in demand. ${ }^{29}$ Dutch citizens benefited greatly from the bank. Because of trust in the continuing value of the currency, interest rates were driven to four percent, and as a result, the Dutch were able to finance domestic and international projects at favorable rates. ${ }^{30}$

artificial prices did not reflect actual costs. Id. This behavior - the willingness to use operation of law to constrain the transactions between private individuals-was commonplace throughout the Greco-Roman empires. See generally RICHARD DUNCAN-JONES, MONEY AND GOVERNMENT IN THE ROMAN EMPIRE (1998).

23. Gerard L. Gutek, A History of the Western Educational Experience 163 (1995).

24. Stephen Quinn \& William Roberds, The Big Problem of Large Bills: The Bank of Amsterdam and the Origins of Central Banking 1, 35-36 (Fed. Reserve Bank of Atlanta, Working Paper No. 2005-16, 2005), http://papers.ssrn.com/sol3/papers.cfm?abstract _id=814004 [https://perma.cc/XP5P-3RU2]; Isabel Schnabel \& Hyun Song Shin, The "Kipper- und Wipperzeit" and the Foundation of Public Deposit Banks 3 (Nov. 2006) (unpublished manuscript), https://www.aeaweb.org/annual_mtg_papers/2008/2008_258.pdf [https://perma.cc/X7ZP-ETNK].

25. Quinn \& Roberds, supra note 24, at 5.

26. Id. at 8; see also Schnabel \& Shin, supra note 24, at 16.

27. Schnabel \& Shin, supra note 24 , at 17.

28. Id. at 16 .

29. Nathan Lewis, Gold: The Once And Future Money 29 (2007).

30. Id.; see also ChristiaAn van Bochove, The ECONOMic CONSEQuences of the DuTch 105 (2008). These books document Dutch loans to Danish kings. While the interest rate was $12 \%$ in 1564 , it was $5 \%$ in 1649 and $3 \%$ in 1723 . See SIDNEY HoMER \& RichARD Sylla, A History of InTERest Rates 126 (4th ed. 2005). 
Currencies then as now competed on the basis of their reliability. One often overlooked contribution of the Bank of Amsterdam is the competitive effect it had on the development of other nations' currency regimes. ${ }^{31}$ From the early decades of the seventeenth century, many in England were initially bitter at the superior prosperity and economic growth enjoyed by the Dutch. ${ }^{32}$ However, instead of following the Dutch example of allowing the market to value its currency based on its intrinsic worth, the British attempted to use law to directly drive economic production rather than create a stable framework for currency which would encourage commerce. ${ }^{33}$ Observing that the rate of interest was lower in Holland than in England, mercantile theorists leapt to the conclusion that the cause of the superior Dutch prosperity was Holland's low rate of interest and suggested lowering interest rates by regulation. ${ }^{34}$

John Locke argued that interest rates could not be regulated in this manner. ${ }^{35} \mathrm{His}$ contribution was reasoning that the prime function of government was not to manipulate interest rates, but simply to maintain a stable currency. ${ }^{36}$ Thus, it should avoid the two basic errors that had previously plagued government-issued currency. First, the government should not engage in debasement. ${ }^{37}$ In condemning debasement as a deceitful government practice he quipped that "[o]ne may as rationally hope to lengthen a foot, by dividing it into fifteen parts, instead of twelve, and calling them inches." ${ }^{38}$ Second, the government should not try to legislate interest rates, which, like price controls on products, was a form of requiring money to be accepted under conditions determined by the government, not by the market. The role of the government in monetary supply was simply to fix the value of a currency to a stable commodity - such as gold or silver. ${ }^{39}$

The maintenance of a stable unit of account contributed greatly to the success of the Bank of England. ${ }^{40}$ Because the bank provided ready access to capital, the

31. John Francis, History of the Bank of England, Its Times and Traditions, From 1694 To 1844, at 322 (1862) (explaining impetus for Bank of England came from success of Bank of Amsterdam).

32. Steven C. A. Pincus, From Butterboxes to Wooden Shoes: The Shift in English Popular Sentiment from Anti-Dutch to Anti-French in 1670s, 38 Hist. J. 333, 337 (1995).

33. Kenneth Morgan, Mercantilism and the British Empire, 1688-1815, in THE POLITICAL ECONOMY OF BRITISH HiSTORICAL EXPERIENCE, 1688-1914, at 165, 171 (Donald Winch \& Patrick K. O’Brien eds., 2002).

34. LEWIS, supra note 29, at 29.

35. See HoMER \& SYLLA, supra note 30 , at 78.

36. Walter Eltis, Britain, Europe AND EMU 231 (2000).

37. 2 JoHn Locke, Further Considerations Concerning Raising the Value of Money, in THE WORKS OF JOHN LOCKE, EsQ. 73 (6th ed. 1759).

38. Id.

39.

The reason why it should not be chang'd is this: Because the publick authority is guarantee for the performance of all legal contracts. But men are absolved from the performance of their legal contracts, if the quantity of silver under settled and legal denominations be altered ... the landlord here and creditor are each defrauded of twenty percent of what they contracted for, and is their due.

Id. at 72 .

40. LEWIS, supra note 29, at 30. 
government was less likely to devalue the currency to finance its operations. ${ }^{41}$ It is said in fact that the new institutions for currency formed during the Enlightenment "form[ed] the basis for the Industrial Revolution and the final sweeping away of the feudal system." ${ }^{42}$

\section{B. Modern Currency Regimes}

\section{A Theory of Modern Central Banking}

Modern central banking has developed against general theories of governance that are quite different from those of John Locke. Modern government is supposed to manage the economy for the benefit of the people. Thus, in keeping with this view, central banks are given more discretionary power to meet objectives other than maintenance of the stable value of the currency. By 1920, the international consensus suggested that a central bank was essential to help a state manage its economy in a sound manner. ${ }^{43}$ Central banks have evolved since then, becoming "powerful in setting and managing domestic policies, with a handful of central banks influential in the international arena, setting trends and norms which other central banks often emulate." ${ }^{44}$ These objectives include promoting economic growth and employment. ${ }^{45}$

It is well understood that the powers granted to a modern central bank raise in acute form the question of whether the government will use its power over currency to help the rulers. The fear is that rulers will use the discretion given to modern central banks to manipulate the currency to advance their reelection or for other partisan ends that are not in the public interest. ${ }^{46}$ Because voters value short-term economic growth, even if that growth comes artificially through inflation,

41. Id.

42. $I d$.

43. Douglas W. Warner, Michael A. Panton \& Paul Legot, Central Banks and Central Bank Cooperation in the Global Financial System, 23 PaC. McGeorge Global Bus. \& Dev. L.J. 1, 3 (2010).

44. Id.

45. See, for example, the goals of the Federal Reserve: 12 U.S.C. $\S 225 a$ (2012), stating that:

[t]he Board of Governors of the Federal Reserve System and the Federal Open Market Committee shall maintain long run growth of the monetary and credit aggregates commensurate with the economy's long run potential to increase production, so as to promote effectively the goals of maximum employment, stable prices, and moderate long-term interest rates.

See generally Gerald Epstein, Central Banks as Agents of Economic Development 103 (Political Econ. Research Inst., Working Paper No. 104, 2005) (stating that central banks are agents of economic development).

46. Christopher Way, Central Banks, Partisan Politics, and Macroeconomic Outcomes, 33 COMP. POL. STUD. 196, 196-99 (2000) ("The distinctiveness of partisan policy preferences implies that the effects of an independent central bank are contingent on who governs."). In this article, Way describes how left- and right-wing governments could use central banks. 
manipulating the money supply to give the economy a sugar high might aid politician reelection. ${ }^{47}$ But in the medium and long run, few win from rampant inflation. ${ }^{48}$

The classic response has been to make central banks independent of politicians to avoid the time inconsistency of popular preferences. ${ }^{49}$ Central bank independence supposedly functions as the formal commitment that ensures politicians do not manipulate the economy in the short run to the long-term detriment of society, even if that helps their short-term electoral interests. ${ }^{50}$ Independence thus helps foster trust in a currency that serves general long-term commercial interests - the kind of objective Locke praised. It is the financial world equivalent of Ulysses tying himself to the mast to resist the call of the sirens. ${ }^{51}$

But even if independent by law from ordinary political actors, most modern central banks must pursue legally established objectives other than maintaining the value of the currency. ${ }^{52}$ Thus, a second problem for central banks in the competition with bitcoin is not lawlessness but legal fidelity - fidelity to these other objectives. The pursuit of goals other than maintaining the value of the currency can create lack of trust in the currency by individual users.

The government can also alter the objectives and independence of a central bank. As a result, citizens cannot easily rely even on their expectations about its objectives under current law. Moreover, the structure of the central bank does not prevent a government from using other powers to undermine the value of and confidence in the currency. Recent history has provided many examples of regimes not only restricting the fair value of exchange with other currencies, but also preventing its currency from being taken outside of the nation's borders. ${ }^{53}$

In the Sections below, we briefly consider the substantial problems that monetarily oppressive regimes have in keeping the confidence of their citizens in their currency. These problems come from both the structure of central banks and the actions of governments outside central banks. Then, we will consider the monetary regime in the United States. While this regime creates more trust than any political regime for currency in the world, its focus on objectives other than maintaining value and its inability to exclude political influence temper that confidence and thus may ultimately give a new type of currency, like bitcoin, opportunities to compete even with money issued by the Fed.

47. Peter Conti-Brown, The Institutions of Federal Reserve Independence, 32 YALE J. ON REG. 257, 263 (2015).

48. Gregory D. Hess \& Charles S. Morris, The Long-Run Costs of Moderate Inflation, 1996 FED. Res. BANK KANSAS City ECON. REV. 71, 84, https://www.kansascityfed.org / /media/files/publicat/econrev/econrevarchive/1996/2q96hess.pdf [https://perma.cc/2V9K $-\mathrm{GD} 2 \mathrm{H}]$.

49. Conti-Brown, supra note 47, at 263 (noting time inconsistency reflects that "our shortterm interests in inflation-based prosperity are in tension with long-term interests in avoiding the economic devastation that this inflation brings"); see also Sylvester C.W. Eijffinger \& Jakob De Haan, The Political Economy of Central-Bank Independence, 19 SPECIAL PAPERS INT'L ECON., May 1996, at 1.

50. Conti-Brown, supra note 47, at 263.

51. Id.

52. See discussion infra Section I.B.3.

53. See discussion infra Section II.B.2. 


\section{Monetarily Oppressive Regimes}

Bitcoin currently provides the most value to monetary regimes that fail to instill confidence in the value of their currency because bitcoin offers a solution for the gap in trust between ordinary citizen and the empowered ruling class. We very briefly consider two regimes which undermine confidence: Argentina and China. In both cases, the problems include lack of confidence in the central bank and actions by the government distinct from the central bank that undermine confidence. Not surprisingly, many citizens of both nations have been enthusiastic bitcoin users.

Perhaps the best example of the relation of a central bank that undermines confidence in the currency was Argentina. For example, in 2010, the president of the country had a plan to use 6.59 billion USD of the country's reserves to pay off foreign debt. ${ }^{54}$ When the governor of the central bank - citing the central bank's independence - refused to comply with this plan, he was dismissed. ${ }^{55}$ In March 2012, the objective of the Argentinian central bank was changed from price stability to a much broader mandate "to promote ... monetary and financial stability, employment and economic development with social equality." ${ }^{" 56}$ Additionally, the ability of the central bank to lend to the government was increased. As such, it is clear that the Argentinian central bank was pursuing several other objectives apart from maintaining the value of the currency, and it was thereby strongly influenced by the government. The result was inflationary pressure on the currency. The government responded to that pressure by preventing citizens from preserving their wealth by exchanging pesos for dollars at a market rate. As a consequence, Argentina saw a substantial rise in bitcoin usage. ${ }^{57}$

China is perhaps even more important for bitcoin today. Whatever the formal guarantees of independence, citizens are unlikely to have confidence in China's central bank because, like every other institution in China, it is ultimately subservient to the dictates of the Communist Party. ${ }^{58}$ Moreover, the government has restricted the ability of people to take their money out of the country-individuals and companies alike. ${ }^{59}$ While such moves are designed to shore up the currency, they

54. Mario Damill, Roberto Frenkl \& Martín Rapetti, Macroeconomic Policy in Argentina During 2002-2013, 57 ComP. ECON. STUD. 369, 390-91 (2015); Guillermo Vuletin \& Ling Zhu, Replacing a "Disobedient" Central Bank Governor with a "Docile" One: A Novel Measure of Central Bank Independence and Its Effect on Inflation, 43 J. MONEY CREDIT \& BANKING 1185, 1186 (2011).

55. Alexei Barrionuevo, Argentine Bank President Is Formally Dismissed, N.Y. TIMES (Feb. 3, 2010), http://www.nytimes.com/2010/02/04/world/americas/04argentina.html [https://perma.cc/S7ZB-K76E].

56. Damill et al., supra note 54, at 391 (internal quotation marks omitted).

57. Rainer Böhme, Nicolas Christin, Benjamin Edelman \& Tyler Moore, Bitcoin: Economics, Technology, and Governance, 29 J. ECON. PERSP. 213, 224 (2015).

58. Stephen Bell \& Hui Feng, How Proximate and 'Meta-Institutional' Contexts Shape Institutional Change: Explaining the Rise of the People's Bank of China, 62 POL. STUD. 197, 201 (2014); Connie Wee-Wee Chung \& Jose L. Tongzon, A Paradigm Shift for China's Central Banking System, 27 J. Post KeYNESIAN ECON. 87, 101 (2004).

59. Böhme et al., supra note 57, at 224; Jinzhao Chen \& Xingwang Qian, Measuring Ongoing Changes in China's Capital Controls: A De Jure and a Hybrid Index Data Set, 38 CHINA ECON. REV. 167, 168 (2016). 
undermine confidence in it. Not surprisingly, from 2013 up through early 2017, Chinese citizens engaged in more bitcoin transactions than the rest of the world combined because of their desire to use bitcoin as an alternative to China's currency and to aid in evading capital outflow restrictions. ${ }^{60}$

China and Argentina have been prime examples of monetarily oppressive regimes that have increased demand for bitcoin. But other nations with monetarily oppressive aspects, including Venezuela and India, have also seen boosted demand for bitcoin from their citizens. ${ }^{61}$

\section{The Example of the Fed}

The Federal Reserve offers the paradigm example of a modern central bank, both in its broad mandate to help the function of the economy and in its structure of putative independence. Its creation at the turn of the twentieth century marked the period known as the Progressive Era, during which the federal government acquired a variety of new powers that were thought to work for the benefit of the people. ${ }^{62}$ The dissatisfaction with the national banking system led to a series of commissions and debates discussing reform, which culminated in the establishment of the Federal Reserve with the enactment of the Federal Reserve Act of $1913 .{ }^{63}$

Over the course of the past century, the Fed has become one of the most important governmental agencies in the history of American society, a transformation one scholar labeled "the most remarkable bureaucratic metamorphosis in American history." ${ }^{44}$ It has broad power to influence the economy by both law and practice. By law, it is obligated to pursue full employment and economic growth as well as seek price stability ${ }^{65}$ In practice, by the actions of its open market committee, it

60. Willy Woo, Estimating China's Real Bitcoin Trading Volumes, CoInDEsK (Jan. 17, 2017, 7:45 PM), https://www.coindesk.com/estimating-data-china-real-bitcoin-tradingvolumes [https://perma.cc/3TA2-8V4A].

61. See, e.g., Luke Graham, India's Rupee Restrictions Are Boosting Demand for Bitcoin, CNBC (Nov. 15, 2016, 8:44 AM), http://www.cnbc.com/2016/11/15/india-rupee-restriction -boost-bitcoin-digital-currency.html [https://perma.cc/CZ9M-3AYZ] (following India's announcement in late 2016 that the 500 and 1000 rupee notes were no longer legal tender, demand for bitcoin in India spiked); Kamilia Lahrichi, Growing Number of Venezuelans Trade Bolivars for Bitcoins to Buy Necessities, GUARDIAN (Dec. 16, 2016, 6:15 AM), https://www.theguardian.com/technology/2016/dec/16/venezuela-bitcoin-economy-digital -currency-bolivars [https://perma.cc/W7RQ-R7M2] (describing the flight to bitcoin in Venezuela); Sophie Morlin-Yron, Could a Digital Currency Bring Africa Closer to China?, CNN (Dec. 23, 2016, 4:54 AM), http://www.cnn.com/2016/12/23/africa/bitcoin-startup-africa [https://perma.cc/H42L-MU4C] (indicating bitcoin provides a unique opportunity to facilitate trade between Africa and China).

62. From Roosevelt to Roosevelt: American Politics ANd Diplomacy, 1901-1941, at 69, 70 (Otis L. Graham, Jr. ed., 1971) (describing rise of new economic power beginning in the Progressive Era).

63. James Forder, 'Independence' and the Founding of the Federal Reserve, 50 ScOT. J. POL. ECON. 297, 299 (2003).

64. Donald F. Kettl, Leadership at The Fed 9 (1986).

65. 12 U.S.C. $\$ 225 a$ (2012). 
substantially influences interest rates, which in turn affect the economy and value of the currency.

As with the theory of central banking generally, the focus on preserving trust in the Federal Reserve has been to guarantee its independence. When comparing bitcoin to the Federal Reserve, that focus on independence is too limited. If bitcoin climbs the rungs of acceptability and competes with the dollar, its success will not build principally on the Fed's current lack of independence but on objectives that may interfere with price stability and the danger and the impossibility of assuring future independence.

Law is at the center of the Federal Reserve's independence: it is the originating statute itself that defines it. ${ }^{66}$ The structure of the Federal Reserve is relatively simple. The seven members of the Federal Reserve Board of Governors are nominated by the President and confirmed by the U.S. Senate. ${ }^{67}$ The full term of a governor is fourteen years, and appointments are staggered so that one term expires in each evennumbered year. ${ }^{68}$ Once appointed, Federal Reserve Governors cannot be removed except for cause. ${ }^{69}$ The lengthy terms and staggered appointments are intended to contribute to the insulation of the board - and the Federal Reserve System as a whole - from the President who might otherwise appoint most of the board. ${ }^{70}$

Many legal academics take this independence as a given. ${ }^{71}$ But the law of independence in action is weaker than the law of independence on the books. ${ }^{72}$ Most importantly, the practice of early resignation by Federal Reserve Board Governors tempers its independence. ${ }^{73}$ This practice has resulted in an appointment process where Presidents can appoint governors at a rate far greater than the Act originally envisioned. ${ }^{74}$

66. Conti-Brown, supra note 47 , at 259.

67. 12 U.S.C. $§ 241$ (2012); Who Are the Members of the Federal Reserve Board, and How Are They Selected?, BOARD GOVERNORS FED. RES. SYS., www.federalreserve.gov/faqs/about_12591.htm [https://perma.cc/YMU6-SWRU].

68. 12 U.S.C. $\S 242$ (2012).

69. Id.

70. Rachel E. Barkow, Insulating Agencies: Avoiding Capture Through Institutional Design, 89 Tex. L. Rev. 15, 24 (2010); Ben S. Bernanke, Chairman, Bd. of Governors of the Fed. Reserve Sys., Central Bank Independence, Transparency, and Accountability, Speech at the Institute for Monetary and Economic Studies International Conference (May 25, 2010) (transcript available at http://www.federalreserve.gov/newsevents/speech /bernanke20100525a.htm?guid=ON [https://perma.cc/RXX8-F43V]). The Chairmen and Vice Chairmen of the Board serve four-year terms and are selected among the seven board members by the President to serve those terms. 12 U.S.C. $\S 242$ (2012).

71. Barkow, supra note 70, at 24.

72. Conti-Brown, supra note 47 , at 260.

73. William R. Keech \& Irwin L. Morris, Appointments, Presidential Power and the Federal Reserve, 19 J. Macroeconomics 253, 255 (1997); Paul D. Mueller, Public and Private Institutions in the Federal Reserve, 31 J. PRIV. ENTERPRISE 49, 55 (2016).

74. Under the principle of staggered terms, Presidents should be able to appoint one governor every other year. But every President except Kennedy has exceeded this rate, and the trend of early turnover has increased in recent times. Mueller, supra note 73, at 55 (noting a trend toward shorter terms). 
But even were the independence of the Federal Reserve in practice to match its ideal, its basic function can undermine trust in the currency because it has both a mandate to pursue objectives other than maintaining the value of the currency and the discretionary powers to do so. Thus, the Fed is to pursue growth and low unemployment as well as price stability. ${ }^{75}$ Moreover, recently, in response to the last financial crisis, many central banks, including the Federal Reserve, engaged in an unprecedented program of quantitative easing whereby the central bank purchased billions in mortgage-backed securities to stem the financial crisis ${ }^{76}$ Precisely because this action is unprecedented, its long-term effects on the economy are hard to predict.

Yet another factor that may lead to lack of trust is Congress's inability to precommit to the independence the Fed enjoys or even to a set of social objectives. The Constitution prohibits legislative entrenchment - the ability for one Congress to bind future Congresses to its own legislation. ${ }^{77}$ Absent constitutional amendment, legislatures cannot ensure that the laws governing today's Fed will be the same as future laws. ${ }^{78}$ In fact, the laws governing the Fed have changed quite significantly since the creation of the Federal Reserve in 1913. ${ }^{79}$

The U.S. government can affect the value of the currency even apart from changing the structure or objectives of the Federal Reserve. Famously, it was President Richard Nixon, not the Federal Reserve, who ended the convertibility of the dollar into gold. ${ }^{80}$

Thus, the Federal Reserve illustrates features in modern central banking that may undermine trust in its capacity to maintain the value of currency, making it vulnerable to competition from other forms of currency. First, it is imperfectly independent from political actors who may want to influence its operations at the expense of monetary stability. Second, and even more importantly, its public objectives of economic growth and full unemployment are in tension with a sole focus on monetary stability. Third, Congress retains the power to further compromise its independence and create still more mandates that may undermine monetary stability. Lastly, the government can influence the value of currency outside the mechanisms of central banking. While the Federal Reserve does indeed create a relatively stable currency free from politics,

75. 12 U.S.C. $\$ 225 a(2012)$.

76. See generally Michael Joyce, David Miles, Andrew Scott \& Dimitri Vayanos, Quantitative Easing and Unconventional Monetary Policy - An Introduction, 122 Econ. J. 271 (2012) (outlining theory and practice of quantitative easing in central banks, including the Fed).

77. McGinnis \& Rappaport, supra note 13 , at 388.

78. Id. at 389.

79. See, e.g., Federal Reserve Reform Act of 1977, Pub. L. No. 95-188, § 2A, 91 Stat. 1387, 1387 (tasking the Federal Reserve "to promote effectively the goals of maximum employment, stable prices, and moderate long-term interest rates"); Banking Act of 1933, Pub. L. No. 73-66, 48 Stat. 162 (creating the Federal Open Market Committee charged with overseeing the nation's open market operations); Act of Feb. 25, 1927, Pub. L. No. 69-640, 44 Stat. 1234 (removing the twenty-year charter and granting the Federal Reserve approval "until dissolved by Act of Congress").

80. Francis J. Gavin, Gold, Dollars and Power: The Politics of International Monetary RElations, 1958-1971, at 11 (2004). 
our review shows that even this excellent central bank ultimately requires trust in the political system and political actors.

\section{The Experiments of Private Law Banking}

In this Section, we consider the most important historic alternative to central banks - private law banking. We first briefly describe why theorists of modern free banking believe that the market can create a sound banking system through private law rather than public regulation. This is a system of trust in the self-interest of private actors, rather than in government regulation and regulators. But we then question whether, even assuming the soundness of such a system, government can be trusted to permit it to flourish. We suggest that two of the periods of relatively free banking in modern history-in Scotland and in the United States-were essentially ended by government.

\section{The Theory of Free Banking}

The Modern Free Banking (MFB) School questions "whether government has any legitimate role to play in producing, or regulating the private production, of monetary assets." ${ }^{\prime 81}$ It has long been thought that banks issuing private currency are liable to failure with resulting panics because they will be tempted to issue notes in excess of their capitalization. ${ }^{82}$ MFB advocates, in contrast, believe that by issuing and circulating private currencies, banks are actually less likely to become overextended. According to MFB advocates, the "overissue of notes or demand deposits will not occur under a laissez-faire monetary regime as long as convertibility of bank liabilities into base money is guaranteed by each bank and the total amount of base money is fixed in supply." 83

Under MFB theory, the functionality and soundness of banks derive from the invisible hand of markets rather than government regulation. ${ }^{84}$ Banks issue their own currency redeemable under specie, such as gold. If they issue too many notes given their capital, users will not take up the notes for fear they will lose value ${ }^{85}$ To increase their notes' salability, banks also will create efficient mechanisms, like

81. Lawrence H. White, Competition ANd CuRrency: EsSAys on Free Banking AND MONEY 48 (1989).

82. Jessica Lautin \& B.J. Lillis, When Banks Were Able to Print Their Own Money Literally, BLOOMBERG (Oct. 19, 2012, 1:36 PM), https://www.bloomberg.com/opinion /articles/2012-10-19/when-banks-were-able-to-print-their-own-money-literally [https:// perma.cc/R29Q-RTGF].

83. Shirley J. Gedeon, The Modern Free Banking School: A Review, 31 J. ECON. IssuES 209, 210 (1997).

84. See George A. Selgin \& Lawrence H. White, How Would the Invisible Hand Handle Money?, 32 J. ECON. LiterATURE 1718, 1719-20 (1994).

85. WHITE, supra note 81, 31-34. 
clearinghouses, to facilitate easy exchange of banknotes. ${ }^{86}$ To make their notes even more attractive and to prevent bank runs, they will also create capital cushions. ${ }^{87}$

Consequentially, in the free banking system, banks create currency to meet public demand, create their own mechanisms of exchange, and do not need to coordinate with any central bank. ${ }^{88}$ Thus, the trust in currency does not directly require trust in a central bank and the political agents that control it.

However, some doubt that trust in the market process itself is enough to discipline banks. ${ }^{89}$ Critics of the MFB school argue that they do not consider conditions that might make it impossible for the holders of private banknotes to repay their loans and for private bankers to refinance positions. ${ }^{90}$ But what seems to be missing from the debate on free banking's merits is any discussion of a simpler question: can any form of laissez-faire banking exist under the shadow of public law? For the same reason that government cannot credibly commit to the independence of public banks from political considerations, they cannot credibly commit to refusing to interfere. As history demonstrates, treasuries will always be tempted in times of crisis or opportunity to end the system of private banking, so they can better control the currency for political purposes..$^{91}$ As a result, the merits of the currencies regulated only by private law remain only theoretical in nature, as any system of private banking will always operate under the shadow of public law and can be crushed by it.

\section{The Termination of Free Banking}

a. The Dissolution of Free Banking in Scotland

Indeed, public law has compromised and ultimately ended experiments in free banking even when the experiments seemed successful. Advocates of the MFB movement argue that Scotland, from 1695 up through 1844, serves as perhaps the best model for how a system of private banking should function..$^{92}$ During this time, Scotland had no central bank and relatively few legal restrictions on the operations of banks. ${ }^{93}$ Moreover, after 1716, the Bank of Scotland enjoyed no substantial monopoly powers. ${ }^{94}$ Some have suggested that that the Scottish private banking

86. Id.; see also Selgin \& White, supra note 84, at 1732-34 (discussing role of clearinghouses in free market banking systems).

87. WHITE, supra note 81, at 234.

88. Gedeon, supra note 83 , at 211.

89. Id. at 220 .

90. Id.

91. See Lawrence H. White, What You Should Know About Free Banking History, CATO InST.: CATO LiBERTY (Apr. 28, 2015, 3:32 PM), https://www.cato.org/blog/what-you -should-know-about-free-banking-history [https://perma.cc/6TSK-F35B].

92. Tyler Cowen \& Randall Kroszner, Scottish Banking Before 1845: A Model for Laissez-Faire?, 21 J. MONEY, CREDIT \& BANKING 221, 222 (1989).

93. Lawrence H. White, Free Banking in Britain: TheOry, ExPERIEnCE AND Debate, 1800-1845, at 23 (1984); Gary Gorton, Banking Theory and Free Banking History: A Review Essay, 16 J. MONETARY ECON. 267, 267-68 (1985).

94. White, supra note 93, at 24-25; Sheila C. Dow \& John Smithin, Free Banking in 
system had real virtues, most importantly in stoking innovation that served consumers. ${ }^{95}$ Others have suggested this free banking system contributed to economic growth in Scotland. ${ }^{96}$

But any success of Scottish banking may well have been a large part of its undoing because it could not successfully compete against the Bank of England in the one place that ultimately counted in the United Kingdom - its Parliament. The Peel Acts brought to a close the period of free banking in Scotland. They prevented new banks from issuing banknotes of their own. ${ }^{97}$ While they grandfathered in the ability of some existing banks to issue notes, they secured the Bank of England's position as a central bank that had privileges that all other banks lacked. ${ }^{98}$ Indeed, the Peel Acts were largely drafted by the Bank of England officials. ${ }^{99}$

\section{b. The Successes and Regulatory Obstacles of Free Banking in the United States}

The use of free banking in the United States is often used as a negative example of free banking. ${ }^{100}$ But it is not clear that history of free banking here supports the view that private banks cannot support a sound economy. It does, however, provide more evidence that private banks exist under the thumb of public law and thus are not likely to survive for the long term.

What has been called the "Free Banking Era" began in 1833 with an executive order by President Jackson that ended the Second Bank of the United States. ${ }^{101}$ Traditionally, bankers and historians have judged the experiments of the Free Banking Era as a failure. ${ }^{102}$ However, reexamination of this period has shown that state banknotes weren't nearly as bad as the older accounts make out. ${ }^{103}$

In fact, the failure rate of these state banks during the Free Banking Era was not particularly high. ${ }^{104}$ Arguably, failure of these state banks was not due to lack of government oversight, but in fact regulations that compelled banks to back their notes with high-risk state bonds. ${ }^{105}$ The poor performance in these states shows that

Scotland, 1695-1845, 39 ScOT. J. PoL. Econ. 374, 380 (1992).

95. C. W. Munn, Scottish Provincial Banking Companies: An Assessment, 23 Bus. Hist. 19, 25 (1981) (detailing innovations which served banking customers).

96. White, supra note 93, at 24; Munn, supra note 95, at 33.

97. WHITE, supra note 93 , at 76.

98. Id.

99. Id. at 76-77.

100. Arthur J. Rolnick \& Warren E. Weber, New Evidence on the Free Banking Era, 73 AM. ECON. REV. 1080, 1083 (1983).

101. Richard Hofstadter, The American Political Tradition: And the Men Who MADE IT 48 (1989). The first states to pass free banking laws were Michigan (1837), New York (1838), and Georgia (1838). Gerald P. Dwyer Jr., Wildcat Banking, Banking Panics, and Free Banking in the United States, 81 Econ. ReV. - Fed. Res. Bank AtLanta, Dec. 1996, at 1, 2, 4; Hugh Rockoff, The Free Banking Era: A Reexamination, 6 J. MonEY CREDIT \& BANKING 141, 142 (1974).

102. Rolnick \& Weber, supra note 100 , at 1083.

103. Id. at 1087; Matthew Jaremski, Free Bank Failures: Risky Bonds Versus Undiversified Portfolios, 42 J. MONEY CREDIT \& BANKING 1565, 1582 (2010).

104. Rolnick \& Weber, supra note 100, at 1084-85.

105. Jaremski, supra note 103, at 1582. 
many systems of private banking in reality reflected an instability caused by the politics of public law, preferring to use banks as instruments to help state politicians. Ultimately, the experimentation of free banking in the United States faced substantial obstacles by 1864 when Congress passed a series of laws that established a new system of federally chartered banks, in part, to finance the war efforts. ${ }^{106}$

These state and federal regulations again illustrate the greatest problem with private banking. Because banks are so important to an economy, politicians in government are always tempted to co-opt private banks for public ends, such as requiring them to hold risky government bonds, or make them scapegoats for economic failures. Private banking effectively depends on public law of the government jurisdictions in which they operate. As a result, trust in private banks, like that in central banks, is related to trust in those governments.

\section{BITCOIN AND THE IMPLICATIONS OF CURRENCY WITHOUT LAW}

Until recently, there has been no widespread currency that has been the creation of something other than legal regimes. Cryptocurrencies, including most prominently bitcoin, have distinctive features that in combination make for a new kind of currency. Bitcoin is censorship-resistant and not controlled by any government and has a hard limit on amount that can be circulated. ${ }^{107}$ This development creates a uniquely innovative mechanism that can potentially perform the functions of currencies without the traditional law of currency. It not only competes with currencies structured under these laws, like those regulating the money supply, but can also offer a platform for ordering commercial transactions without as much use of formal law.

Order without some forms of law is nothing new. But previously most forms of order without law depended on relatively close-knit communities. Thus, the most famous example of order without law in legal literature occurred when denizens of a county in South Dakota sustained an order regulating cow grazing without following formal rules. And there is no doubt that at times close-knit groups of individuals generate norms that maximize welfare, showing that law is not necessarily a prerequisite to social order. ${ }^{108}$ Yet while neighbors may be able to settle property disputes efficiently without a legal system, when the social distance between individuals increases, and the magnitude of disputes grows, disputants are increasingly likely to turn to legal rules. But bitcoin's order without a law of currency regulates a supply of money and offers a payment system used by hundreds of thousands of people who have never met, dealing in potentially the equivalent of

106. Kurt Schuler, Note Issue by Banks: A Step Toward Free Banking in the United States?, 20 CATO J. 453, 455-56 (2000).

107. The processing power of the bitcoin network is just over one exaflops - or $10^{18}$ floating operation points per second. For perspective, that amount of processing power is more than six times greater than all the top 500 supercomputers combined. Grant Brunner, The Bitcoin Network Outperforms the Top 500 Supercomputers Combined, EXTREMETECH (May 13, 2013, 3:15 PM), http://www.extremetech.com/extreme/155636-the-Bitcoin-network -outperforms-the-top-500-supercomputers-combined [https://perma.cc/D2PX-DFT8].

108. ElLiCKSON, supra note 10, at 267. 
millions of dollars. It is order without law with global reach and on a scale not previously seen.

Additionally, most social mechanisms for enforcing order are quite imperfect. Some people are willing to pay the costs of ostracism or negative gossip or whatever are the adverse consequences of flouting social order. And law can regularly disrupt social norms: the threat of jail or fines ordered by the government overpowers the enforcement mechanisms of most social norms. But bitcoin uses encrypted software to enforce its form of order without law. The power of software permits bitcoin to create and transfer money through a process from which individuals cannot defect and which even the state has great difficulty disrupting. Bitcoin is not only an order of a potential currency without currency law, it is an order resistant to law that would destroy its regime. These characteristics permit it to compete with currencies that are backed by law.

Why is bitcoin resistant to a modern-day Peel Act, in which the state decides that it no longer will tolerate its existence? To be clear, bitcoin is not immune to any action that seeks to legislate it. For the foreseeable future, the market will certainly react when nations either embrace or try to restrict bitcoin.

However, bitcoin's closest technological cousin, the internet, serves as a useful analogy to how technology can disrupt institutions that sovereigns may wish to monopolize. Bitcoin is to currency what the internet is to information. Like the internet, bitcoin is multijurisdictional, and thus one sovereign cannot shut it down. Miners can move elsewhere, and people can use it elsewhere. Additionally, if bitcoin proves to be popular and widely used, its advocates will make it difficult for governments to shut it down even within personal jurisdictions. There the analogy may be to the popularity of another technology phenomenon-Uber-which despite its disruption of incumbent taxi companies, is taking ever greater market share. ${ }^{109}$

Moreover, we are already seeing that some important governments are embracing bitcoin. In the spring of 2017, Japan moved to stamp out fraud in the bitcoin ecosystem. It regulated bitcoin exchanges by requiring them to be audited and to follow a "know your customer" law. ${ }^{110}$ But in April 2017, Japan also moved to accept bitcoin as a legally recognized prepaid payment instrument, like a debit card, that

109. Uber serves as a useful comparison in demonstrating this effect. Throughout Uber's short history, Uber faced immense challenges from legislatures across the globe. See Peter Diamandis, Uber vs. the Law (My Money's on Uber), Forbes (Sep. 8, 2014, 3:34 PM), http://www.forbes.com/sites/peterdiamandis/2014/09/08/uber-vs-the-law-my-moneys-on -uber/\#6e171d491fd8 [https://perma.cc/9STR-K95H]. For example, within the United States, taxi lobbies have put enormous pressure to block Uber drivers from being able to legally operate. $I d$. Uber has continued to grow its operations and valuation despite coordinated effort to undercut it through force of law.

110. Kevin Helms, Japanese Bitcoin Exchanges Implement Stricter KYC Requirements, BitcoIN.COM (Mar. 28, 2017), https://news.bitcoin.com/japanese-exchanges-kyc -requirements [https://perma.cc/EJ2D-55HS]. 
can be used to pay for goods and services. ${ }^{111}$ The result has been greater interest in Japan in using bitcoin. ${ }^{112}$

In the United States, the Securities and Exchange Commission (SEC) received an application to create an exchange-traded fund (ETF) to hold bitcoin. ${ }^{113}$ Such a fund would make it easier for people to participate in the bitcoin ecosystem because they would not actually have to hold bitcoins but could simply buy the fund. The SEC rejected this application, principally because of fears that there was fraud in buying and selling bitcoin through the kind of exchanges presently used, and because the market for bitcoin is not very liquid. ${ }^{114}$ This reasoning in our view is not entirely sound because the ETF would be a vehicle by which ordinary citizens could avoid fraud in the buying and selling of bitcoin and would make the market even more liquid than it is. An ETF, like the recent Japanese law, will likely increase the demand for bitcoin. And as described in more detail below, exchanges in the United States have established futures markets in bitcoin, which may not only help temper volatility in the long run, but promote greater use of the innovation.

More generally, developments like those in Japan and the United States show how bitcoin can gain a stronger presence in the legal and economic systems of the developed world. As bitcoin becomes more popular and more intertwined with a nation's financial system, it becomes harder for that government to move against it. The longer the world goes without an economic crisis, the more opportunity bitcoin will have to become ingrained in the financial system and avoid being made a scapegoat for an economic disaster. And so long as there are some jurisdictions in which it is legal, it becomes more difficult for governments in other jurisdictions to prevent citizens from using it.

This Section describes the mechanics of bitcoin and shows how it creates a system of decentralized trust that can operate outside the law. Bitcoin uses software to create a self-enforcing order without law in two interlocking ways. First, bitcoin's algorithm creates an encrypted payment system that is verified by a decentralized ledger - the so-called blockchain. That form of order replaces the structure of currency that needs middlemen like banks to execute monetary transactions between parties. Second, for a time specified by the algorithm, bitcoin pays some of the verifiers of the ledgers in bitcoin. The algorithm thus both creates bitcoin and limits the amount created. This aspect of the algorithm replaces the laws by which central banks control the money supply. We end by discussing the community whose decentralized order ultimately is responsible for bitcoin - the miners who process its

111. Garrett Keirns, Japan's Bitcoin Law Goes into Effect Tomorrow, CoINDESK (Mar. 31, 2017, 3:01 $\quad$ PM), http://www.coindesk.com/japan-bitcoin-law-effect-tomorrow [https://perma.cc/UQ8E-2F37].

112. Tyler Durden, Bitcoin Tops $\$ 1100$ as Japanese Payments Law Goes into Effect, ZEROHEDGE (Apr. 2, 2017, 2:00 PM), http://www.zerohedge.com/news/2017-04-02/bitcoin -tops-1100-japanese-payments-law-goes-effect [https://perma.cc/AZ2M-6QFL].

113. Garrett Kerins, From First Filing to Final Decision: The Journey of the Winklevoss Bitcoin ETF, COINDESK (Mar. 9, 2017, 9:34 PM), http://www.coindesk.com/the-journey-of -the-winklevoss-bitcoin-etf [https://perma.cc/P2B4-LP2H].

114. Bats BZX Exch., Inc., Order Setting Aside Action by Delegated Authority and Disapproving a Proposed Rule Change, Exchange Act Release No. 34-83723 (July 26, 2018), https://www.sec.gov/rules/other/2018/34-83723.pdf [https://perma.cc/H7SJ-GHM8]. 
blockchain - and explain why their incentives favor the maintenance of bitcoin's value as a currency.

\section{A. The Innovation of Decentralized Trust}

The birth of the information age has been characterized by a shift from traditional industries born in the Industrial Revolution to an economy based on information and computerization. As venture capitalist Marc Andreessen put it: "software is eating the world." 115 This phrase encapsulates the phenomena that evolved over the past few decades where software companies have been able to reinvent industries and displace competitors who were unable to adapt as quickly to the "software revolution." From Amazon displacing the retail book industry, to Netflix displacing Blockbuster and the video rental industry, and most recently, to Uber's displacement of the 100-year-old taxi industry, software has been upending every corner of the global economy.

But while technological innovations have consistently been a disruptive force, they are often met with skepticism. No innovation in recent history faced this initial hurdle more than the internet. In the early 90s, while internet enthusiasts were touting its ability to change the world through a future of telecommuting workers, interactive libraries, and multimedia classrooms, industry giants and mainstream media mainly wrote off the internet as a toy for hobbyists. ${ }^{116}$

But the average consumer now takes the internet for granted, even if they know nearly nothing about how it works. ${ }^{117}$ And while scam artists sometimes exploit the internet, the average American trusts the internet enough to exchange the most sensitive of personal information on it. In fact, all modern financial institutions depend on the internet for the validation of transactions despite the frequency of cyberattacks. ${ }^{118}$

Ever since bitcoin began receiving mainstream media attention, its critics have echoed concerns resembling those expressed by commentators during the early years of the internet's existence. ${ }^{119}$ Yet while the institutions that bitcoin is seeking to disrupt may be fundamental, the technology underlying bitcoin is not; it is merely the next point of innovation in the software revolution - the same revolution that created Amazon, Facebook, Uber, and Airbnb. By framing the conversation around

115. Marc Andreessen, Why Software Is Eating the World, Wall St. J. (Aug. 20, 2011), https://www.wsj.com/articles/SB10001424053111903480904576512250915629460 [https:// perma.cc/TQ2C-4YJC].

116. See, e.g., Clifford Stoll, Why the Web Won't Be Nirvana, NewsweEK (Feb. 26, 1995, 7:00 PM), http://www.newsweek.com/clifford-stoll-why-web-wont-be-nirvana-185306 [https://perma.cc/VQ7X-PZCQ].

117. Jack Linshi, Study: Most Americans Don't Understand How the Internet Works, TIME (Nov. 25, 2014), http://time.com/3602105/internet-knowledge-test-pew [https:// perma.cc/QNE6-JX6W].

118. Pew Research Ctr., Cyber Attacks Likely to InCrease (2014).

119. See, e.g., Tyler Cowen, How and Why Bitcoin Will Plummet in Price, Marginal REVOLUTION (Dec. 30, 2013, 7:49 AM), http://marginalrevolution.com/marginalrevolution /2013/12/how-and-why-Bitcoin-will-plummet-in-price.html [https://perma.cc/T5TQ-A4YS]. 
bitcoin as radical, untrustworthy, and impractical, the lessons learned from the previously disruptive force of software are ignored.

But any serious debate on bitcoin requires a baseline understanding of how the technology functions. This next Section offers a rudimentary understanding on bitcoin mechanics and an appreciation of why the technology itself is groundbreaking.

\section{B. Bitcoin Explained}

From the perspective of a consumer, bitcoin is nothing more than a mobile app or computer program that allows users to send digital tokens - the bitcoins themselves - to any other consumer who has downloaded a bitcoin application. ${ }^{120}$ At face value, this seems unimpressive. In fact, companies like Venmo and PayPal seem like superior platforms, as they allow individuals to exchange actual fiat currency. To understand why bitcoin is innovative requires an analysis of the challenges to creating a digital currency that is not attached to fiat. ${ }^{121}$

There is a fundamental difference between exchanging currency in a person-toperson transaction versus exchanging data over the internet. When two people engage in a transaction for one dollar, both parties can be confident that the transaction has occurred. The buyer can look and feel that there is one less dollar in his wallet, while the seller can touch and feel the physical dollar handed over. Even when money is represented digitally, as in the value of a bank account, its digital representations can ultimately be cashed out in dollar bills. A check covers the value of a brokerage account when liquidated, and that check by the operation of law can be exchanged for currency. Thus, a structure of commercial law facilitates payments at a distance. ${ }^{122}$

Creating a decentralized currency over the internet poses a unique issue-how can one trust that a unit of digital currency has any value without some sort of tangible bill or coin for which it is ultimately redeemable by operation of law? This is the challenge that the creator(s) of bitcoin set to solve. ${ }^{123}$ At its core, a bitcoin is just a string of computer code. ${ }^{124}$ Typically, computer code can be replicated with

120. Frequently Asked Questions, BITCOIN, https://Bitcoin.org/en/faq [https://perma.cc /2YNN-TSXB].

121. The following breakdown of bitcoin's mechanics is inspired by a 2013 blog post. See Nick Custodio, Explain Bitcoin Like I'm Five, MEDIUM (Dec. 12, 2013), https:// medium.com/@nik5ter/explain-bitcoin-like-im-five-73b4257ac833\#.1ccfn8kmp [https:// perma.cc/MJD7-HM4K]. There are numerous online resources that explain bitcoin in varying degrees of functional and technical depth. The remainder of this Article will rely on several of these resources, but for a more in-depth resource on topics ranging from cryptocurrencies, the implications of both public and private blockchains, and the potential application of smart contracts, we recommend MASTERING Bitcoin: Unlocking Digital Cryptocurrencies (2015), by Andreas M. Antonopoulos.

122. Joseph H. Sommer, Where Is a Bank Account?, 57 MD. L. Rev. 1, 61 (1998).

123. While there have been many speculations as to the creator of bitcoin, known by the pseudonym Satoshi Nakamoto, there is no conclusive evidence as to bitcoin's creator. See Who Is Satoshi Nakamoto?, COINDESK (Feb. 19, 2016), http://www.coindesk .com/information/who-is-satoshi-nakamoto [https://perma.cc/JF3T-8T7T].

124. See Michael Nielsen, How the Bitcoin Protocol Actually Works, DATA-Driven 
relative ease. Take, for example, any document lying on your desktop. Any competent computer user knows that they can right click that icon and make an identical copy. With documents, this basic functionality of the computer is desirable. With a digital currency, it is fatal.

Consider, for example, the hypothetical bitcoin user Todd. Todd has some bitcoins and wants to send a few to his friend Alex. Since at its core bitcoin is just a string of computer code, how can we trust Todd not to copy and paste his bitcoins and send the same bitcoins to more than one person? And even if we can trust Todd not to game the system, how can Todd be sure that someone else doesn't steal his bitcoins?

But Todd's an honest man and wants to legitimately transfer his friend Alex some bitcoins. So, Todd decides he is going to announce to everyone on the internet: "I am giving Alex some bitcoins." Todd signs the message with a private digital signature that only he has access to, and now the whole world can see that Todd has given Alex some bitcoins. ${ }^{125}$

Todd still has a problem. How do we quantify what Todd gave to Alex? Todd needs a way for his digital money to act as a unit of account. Understanding this issue, Todd modifies his digital message to Alex: "I am Todd, and I am giving Alex one bitcoin, with serial number 12345."

However, like any transaction involving currency, this transaction requires trust. ${ }^{126}$ In this case, trust begins by requiring Alex to trust that Todd gave him a bitcoin. Historically, trust is created through some centralized authority. To enable their bitcoin transactions, Alex and Todd could rely on a so-called Bank of Bitcoin to create a ledger which keeps track of everyone's bitcoin account. This bank would track all bitcoin serial numbers and their ownership, as well as verify the legitimacy of transactions. Now, when Todd wants to transfer his bitcoin to Alex, he signs the message "I, Todd, am giving Alex one bitcoin, with serial number 12345." Before Alex accepts that the transaction is complete, he must ensure that: (1) the bitcoin with serial number 12345 belonged to Todd at the time of the transaction, and (2) Todd has in fact requested a transfer of that bitcoin to Alex's account. Once Alex has

INTELLIGENCE (Dec. 6, 2013), http://www.michaelnielsen.org/ddi/how-the-bitcoin-protocol -actually-works [https://perma.cc/KXF6-99NR].

125. The idea of a private key resembles an ATM pin, that is, a secret number that allows only one person to spend money from the account. Any person who opens an online wallet with bitcoin is randomly assigned a private key which can either be written on a piece of paper or saved digitally in a computer file. See Private Key, BITCOIN WIKI, https:// en.Bitcoin.it/wiki/Private_key [https://perma.cc/G3PX-XF3U].

126. In traditional bank-to-bank transactions, trust is created by a third party. In the United States, the automated clearing house $(\mathrm{ACH})$ system is a network through which banks send each other "batches of electronic credit and debit transfers." Automated Clearinghouse Services, BOARD GOVERNORS FED. RES. SYS., https://www.federalreserve.gov /paymentsystems/fedach_about.htm [https://perma.cc/2SJS-HTWW]. The ACH is responsible for moving $\$ 43$ trillion worth in financial transactions each year. ACH Network: How It Works, NACHA, https://www.nacha.org/ach-network [https://perma.cc/MZP5 -9 VG4]. However, centralized trust comes at a cost: transaction fees processed by the ACH range between $\$ 0.15$ and $\$ 0.95$, costing financial institutions roughly $\$ 20$ billion a year. $A C H$ Processing Fees, FIRST ACH, https://www.firstach.com/front/ACH-Processing-Fees.html [https://perma.cc/84H9-5BWD]. 
verified these events, he can trust that the transaction is complete and celebrate the fact that he is now one bitcoin richer. ${ }^{127}$

Bitcoin now resembles a modern version of the private bank issued currencies that work by operation of law, as discussed in Part I. But what transforms bitcoin into a currency of order without law rather than one backed by law is the replacement of the centralized Bank of Bitcoin by a decentralized public ledger-the blockchain. The blockchain itself is not much more than a single giant spreadsheet that keeps a historical record of all transactions. ${ }^{128}$ Bankers and accountants call that a ledger. Any ledger needs to be maintained by someone whose role it is to make sure the data accurately reflects the state of transactions.

The naïve way of achieving a public ledger is to assume that everyone using bitcoin will keep a complete record of which bitcoins belong to which individuals. ${ }^{129}$ With the bank removed, when Todd goes to send Alex bitcoin 12345, Alex checks his copy of the blockchain and sees that bitcoin 12345 is Todd's to give. Alex now announces to everyone in the bitcoin network Todd's transaction. Other members of the bitcoin network now double-check to see if Todd in fact owns bitcoin 12345. Once a sufficient ratio of people has confirmed Todd's ownership, everyone updates their blockchain to reflect that bitcoin 12345 now belongs to Alex. Since the bookkeeping is now managed by every user in the bitcoin network, the Bank of Bitcoin no longer acts as a middleman.

However, this system cannot work. It is irrational to think that everyone is willing to keep a personal bitcoin ledger and use computational resources to validate all transactions. To put it in economic terms, the creation of such a ledger imposes too many transaction costs for an order supporting currency to emerge.

Bitcoin's greatest innovation is the creation of a framework that incentivizes some people to do the work of validating transactions while making it possible for others to simply take advantage of the bitcoin platform. To accomplish this, bitcoin's creators also needed to impose an artificial cost for network users to validate transactions, otherwise there would be no barrier to one person or organization validating all the transactions themselves. And very few would trust a currency validated by a single entity. ${ }^{130}$

127. It should be appreciated that the type of transaction described becomes further complicated when Alex and Todd hold their bitcoins at separate banks.

128. This Section doesn't explain how advancements in digital cryptography have made bitcoin possible. For a layman-friendly explanation on how this cryptography works, see Chris Pacia, Bitcoin Explained Like You're Five: Part 3 - Cryptography, EsCAPE Velocity (Sept. 7, 2013), https://chrispacia.wordpress.com/2013/09/07/Bitcoin-cryptography-digital -signatures-explained [https://perma.cc/MU34-39QS].

129. The bitcoin blockchain is essentially a transaction database that contains every transaction ever executed in the currency. The blockchain is publicly available on the internet, and with it, one can find out how much value belonged to each bitcoin address at any point in history. See Block Chain, BITCOIN WIKI, https://en.Bitcoin.it/wiki/Block_chain [https:// perma.cc/7SVK-6LUV].

130. For a brief discussion on bitcoin's mining incentives, see Chris Pacia, Bitcoin Mining Explained Like You're Five: Part 1 - Incentives, EscAPE Velocity (Dec. 27, 2012), https://chrispacia.wordpress.com/2016/12/27/can-bitcoin-exist-only-as-a-store-of-value [https://perma.cc/H3DQ-YHNZ]. 
The cost comes in the form of the electrical power required to solve a computational puzzle, known as proof of work. ${ }^{131}$ The people who do this work are called miners. ${ }^{132}$ To allow this proof-of-work concept to succeed, the miners need to be rewarded for their effort; otherwise there would be no reason for them to expend computational resources and the accompanying electric bills. Miners are now compensated in the form of newly minted bitcoins. ${ }^{133}$ Bitcoins are rewarded to the first miner to solve the computational puzzle associated with a new set of transactions, otherwise known as a "block." ${ }^{34}$ Therefore, the more computational power a miner has, the more bitcoins he is likely to be rewarded.

However, to incentivize people to continue verifying transactions even after the cessation of bitcoin minting, the protocol provides miners with a second source of revenue: transaction fees. When listing a transaction, the buyer and seller can also offer to pay a transaction fee, which is a bonus payment to whatever miner solves the puzzle required to make a block (a batch of transactions to be added to the full ledger) and includes the buyer-seller transaction in that new block. These fees are optional, but $97 \%$ of the transactions in 2014 included a fee, most often set at a default rate of 0.0001 bitcoin. In relative terms, the transaction fees are, on average, below $0.1 \%$ of total transaction value. ${ }^{135}$ In comparison, domestic credit card fees can vary anywhere from $2 \%$ to $4 \%$ of the cost of transaction. ${ }^{136}$

131. See infra Section III.B.6 for a more detailed discussion about bitcoin energy consumption.

132. See Nathaniel Popper, Into the Bitcoin Mines, N.Y. Times: DeALBooK (Dec. 21, 2013, 1:42 PM), http://dealbook.nytimes.com/2013/12/21/into-the-bitcoin-mines [https://perma .cc/62TL-W4BP] (describing the bitcoin mining technology and the miners' roles in the bitcoin system).

133. This system of money creation is very different than any form of fiat in either a public or private currency system. Under this system, newly minted bitcoin enters the economy at a predetermined rate that is not subject to political or economic influence. This Article will explore this mechanic in greater detail in Section II.C.

134. Currently, there is a limit to the amount of bitcoin transactions that can fit into a block. In bitcoin's first few years, this was never an issue, as the transaction volume was not large enough to exceed the amount of information that could fit into each block. However, as bitcoin's adoption has grown substantially, the amount of information that can fit into each "block" is not sufficient to handle current transaction volumes. This transaction limit issue will be explored in greater depth in Section III.B in our discussion on how bitcoin governs itself.

135. Miner Fees, BITCOIN WIKI, https://en.bitcoin.it/wiki/Miner_fees [https://perma .cc/P4XH-A9XY]. While its causation will not be explored in this Article, the authors note that 2017 saw a controversial surge in bitcoin transaction fees. See Timothy B. Lee, Bitcoin Fees Are Skyrocketing, ARS TECHNICA (Dec. 11, 2017, 10:42 AM), https://arstechnica .com/tech-policy/2017/12/bitcoin-fees-are-skyrocketing [https://perma.cc/V2KC-AMQC].

136. This cost is typically incurred by the retailer. American Express charges around 2.5$3.5 \%$ of the overall transaction while Visa and Mastercard fees are typically in the 1.5-2.5\% range. Lindsay Konsko, Why Don't More Retailers Accept American Express?, NERDW ALLET (Mar. 8, 2019), https://www.nerdwallet.com/blog/credit-cards/retailers-accept-americanexpress [https://perma.cc/RM6W-STQK]. Additional fees may be passed onto the consumer when making payments abroad. See Ed Perkins, The Worst Credit Card Gotchas to Avoid When You Travel, SMARTERTRAVEL (Feb. 1, 2016), https://www.smartertravel .com/2016/02/01/the-worst-credit-card-gotchas-to-avoid-when-you-travel 
Thus, even after 2040, when few bitcoins will be left to be minted, ${ }^{137}$ there will still be incentives for miners to maintain the bitcoin blockchain. As the technology becomes more established and more widely accepted, transaction fees could increase without substantially depressing demand. The fees would then progressively replace bitcoins themselves as the payment for miners.

Miners prioritize processing transactions with the highest transaction fee first, so that persons offering a higher transaction fee will see their transactions processed quicker. This incentive-based supply and demand system resembles what companies like Uber have done with surge rates in the ride sharing industry. ${ }^{138}$ In theory, ${ }^{139}$ bitcoin transaction fees should settle at the point where the reward equals the cost of computing the transaction. ${ }^{140}$

What if miners reach different conclusions about a transaction? Usually, when a group of computers or electronic devices must all agree to something, a centralized control unit makes that call and then broadcasts it to the rest of the network. In bitcoin, "distributed consensus" means that the various miners that make up the network must come to an agreement much in the same way that humans reach consensus - with each member contributing their own perspective, and the group coming to a collective decision. ${ }^{141}$ When a miner validates a group of transactions, other miners must agree with its version of the network's transaction history. The distributed consensus is formed when the majority of the computing power commanded by miners in the network confirms the proposed version of the transaction history.

If someone tries to lie to the network, it is in the self-interest of the other miners, who each have their own version of the network's transaction history, to call them out and reject it. The only way for a malicious user to manipulate the distributed consensus and have their own fake version of the transaction history accepted as the truth is by performing what is called a " $51 \%$ attack." 142 A $51 \%$ attack requires the malicious individual to have more computing power than the rest of the network

[https://perma.cc/4887-P8PJ].

137. By design, the rate at which bitcoins are released is cut in half roughly every four years. See Controlled Supply, BITCOIN WIKI, https://en.bitcoin.it/wiki/Controlled_supply [https://perma.cc/DSX6-7VUW]. In 2040, roughly 98\% of the 21 million bitcoins set for production will be distributed.

138. However, unlike Uber surge rates, bitcoin transaction fees are determined by bitcoin users directly, and not indirectly like Uber's internally controlled algorithm. See Utpal M. Dholakia, Everyone Hates Uber's Surge Pricing - Here's How to Fix It, HARv. Bus. Rev. (Dec. 21, 2015), https://hbr.org/2015/12/everyone-hates-ubers-surge-pricing-heres-how-tofix-it [https://perma.cc/9FE2-ZJVJ].

139. Currently, there is a technical constraint on this equilibrium. This Article will explore the debate surrounding the solution to this technical constraint in Section III.B.

140. See Nicolas Houy, The Economics of Bitcoin Transaction Fees (GATE Groupe d'Analyse et de Théorie Économique Lyon-St Étienne, Working Paper No. 1407, 2014), http://papers.ssrn.com/sol3/papers.cfm?abstract_id=2400519 [https://perma.cc/9UGG-86L8].

141. Fraida Fund, Bitcoin: Reaching Consensus in Distributed Systems, WITEST LAB NYU PolyteCHNiC SCH. ENGINEERING (Mar. 7, 2016), https://witestlab.poly.edu/blog/get-rich-onfake-Bitcoins [https://perma.cc/3ZWE-39NS].

142. $51 \%$ Attack, LEARN CRYPTOGRAPHY, https://learncryptography.com/cryptocurrency 151-attack [https://perma.cc/DU4W-J3RT]. 
combined to form a majority consensus in his own right. Since the computing power on the bitcoin network is nearly 100,000 times larger than the world's 500 fastest supercomputers combined, ${ }^{143}$ it is insuperably difficult to fake consensus.

\section{The Nonlegal Order of Bitcoin}

Unlike any modern currency, bitcoin's rules were designed by computer scientists absent oversight by lawyers or bureaucrats. ${ }^{144}$ Bitcoin's architecture allows for monetary transactions between parties at distance, ${ }^{145}$ a prescribed path of money creation over time, ${ }^{146}$ and a complete, public transaction history. ${ }^{147}$ Anyone can create a bitcoin account, without charge and without any centralized vetting procedure - or even a requirement to provide a real name. ${ }^{148}$ Collectively, these rules yield a system that is understood to be more flexible, more private, and less amenable to regulatory oversight than other forms of payment. Since the minting of the first bitcoin in January 2009, bitcoin has seen remarkable growth in terms of its use, adoption, and economic value:

143. Eric Holthaus, Bitcoin Mining Guzzles Energy — and Its Carbon Footprint Just Keeps Growing, WIRED (Dec. 6, 2017, 9:00 AM), https://www.wired.com/story/bitcoin-miningguzzles-energyand-its-carbon-footprint-just-keeps-growing [https://perma.cc/PLA3-C8HB].

144. See generally Böhme et al., supra note 57.

145. Unlike credit card payments, any transaction issued with bitcoin cannot be reversed; they can only be refunded by the person receiving the funds. See Some Things You Need to Know, BiTCOIN, https://Bitcoin.org/en/you-need-to-know [https://perma.cc/5FPN-2DT4].

146. The maximum amount of bitcoins in existence will never exceed 21 million. See Controlled Supply, supra note 137.

147. A full copy of a currency's blockchain contains every transaction ever executed in the currency. With this information, one can find out how much value belonged to each address at any point in history. See Blockchain, BITCOIN WIKI, https://en.Bitcoin.it/wiki/Block_chain [https://perma.cc/7SVK-6LUV].

148. Creating a completely anonymous bitcoin wallet requires a user to take additional steps than simply opening an account on a public exchange, such as Coinbase. However, anonymous transactions in bitcoin are possible for those who truly wish to remain hidden. See Dean Walsh, How to Use Bitcoin Anonymously, CRYPTORIALS (May 22, 2015), http://cryptorials.io/how-to-use-Bitcoin-anonymously [https://perma.cc/56LT-5YM8]. 
Figure 1. BITCOIN ACTIVITY TO DATE (AS OF JUN. 29, 2019) (19 $^{14}$

\begin{tabular}{|l|l|}
\hline Total Bitcoins Minted & $\sim 17.79$ million \\
\hline Market Price (USD) & $\sim \$ 11,900$ \\
\hline Market Cap (USD) & $\sim \$ 207,500,000,000$ \\
\hline Transactions per Day & $\sim 394,000$ \\
\hline $\begin{array}{l}\text { Estimated Daily Transaction } \\
\text { Volume }\end{array}$ & $\sim \$ 300,000,000$ \\
\hline
\end{tabular}

From a jurisprudential viewpoint, the most important aspect of bitcoin is how it creates a mechanism that can support a currency without law of currency in both the creation of the money supply and its payment system. It thus marks a sharp break from the view that currencies are always fundamentally creatures of law. In modern central banking systems, agents of the state make discretionary decisions about the money supply to achieve social objectives. However, in a fully decentralized monetary system, like bitcoin, no centralized authority regulates the monetary base. The bitcoin algorithm defines both how currency is created through the mining process and at what rate.

Scarcity is necessary for any money to have value, not only because scarcity binds the growth of a monetary base and facilitates price stability, but also because it helps protect against counterfeit. ${ }^{150}$ Unlike any modern fiat systems, bitcoin achieves scarcity absent the legal rules that govern the authority of centralized banks to print money. ${ }^{151}$

It is able to accomplish this because, unlike governments that may compel action through legislation, bitcoin is a system of rules that relies on private, voluntary ordering for establishing features that make for a viable currency. One of the most important of these rules was the private decision, made by Satoshi Nakamoto and encoded into the genesis of the bitcoin protocol, to limit the number of bitcoins that can ever be made. Approximately every four years, the rate of newly minted bitcoins rewarded is cut in half. ${ }^{152}$ After all 21 million bitcoins have been created - an event estimated to occur in 2140 - no further bitcoins will issue. ${ }^{153}$ In stark contrast to a central banking authority, this design enables a predictable "expansion of the currency and an ultimate limit to the number of bitcoins issued." 154 This feature may give it an advantage in trust over fiat currencies.

149. Blockchain Charts, BLOCKCHAIN, https://www.blockchain.com/en/charts [https://perma.cc/X8GH-XDHP].

150. Böhme et al., supra note 57, at 215 .

151. Id.

152. Controlled Supply, supra note 137.

153. Gareth Jenkinson, A Glimpse into the Future - What Happens When There Are No More Bitcoin to Mine?, CoINTELEGRAPH (May 6, 2018), https://cointelegraph.com/news/a -glimpse-into-the-future-what-happens-when-there-are-no-more-bitcoin-to-mine [https:// perma.cc/9HZ8-NPTV].

154. Böhme et al., supra note 57, at 218. 
The payment system also represents a new form of private, voluntary order. The decentralized ledger verifies that payments have been made. This incentive-based system of decentralized authority enables each individual bitcoin to be readily traced back through all transactions in which it was used, and thus to the start of its circulation. All bitcoin transactions are readable by everyone in records stored in a widely replicated data structure. ${ }^{155}$ The method of verification is defined by an algorithm - a kind of code to be sure, but not a legal code. In contrast, modern verification of payments depends on a middleman acting under the operation of law. A bank verifies that the buyer has enough money in his account to buy groceries from a seller. Its trustworthiness depends in part on the laws and regulations that permit parties to sue the bank for failure to act responsibly.

This verification process of bitcoin also helps eliminate another problem for fiat currencies: counterfeiting. ${ }^{156}$ In fiat currencies, law is the last line of defense against counterfeiting. Counterfeiters are prosecuted and subject to heavy penalties. But bitcoin counters counterfeiting with the governance system set up by its algorithm. Consistent with the internet's open architecture, anyone can connect multiple computers to the bitcoin system. However, voting on the authenticity of a block (batch of transactions) requires first working to solve a mathematical puzzle that is computationally hard to solve and imposes a not insignificant cost-electricity. Instead of "one person, one vote," bitcoin's "proof of work" scheme implements the principle of "one computational cycle, one vote." 157 Through this design, the proofof-work mechanism simultaneously discourages creating numerous fake identities and provides incentives to verify the blockchain.

Bitcoin's community of miners and their self-regulation is at the foundation of an order for currency without a law of currency. Miners serve as the gatekeepers to the underlying computer logic that not only produces bitcoins, but also validates all bitcoin transactions. But like any computer logic, updates are sometimes needed. Vulnerabilities in security are unearthed. Sometimes, as Part III will explore, fundamentally different visions for bitcoin need to be resolved. But unlike a government, which operates according to public authority, or even a corporation resolving disputes under the terms of its operating agreement, the community of individuals who participate in mining bitcoin have no legal mechanism to resolve disputes.

The ingenuity in bitcoin lies not only in the physical code—which as discussed above, provides a payment platform with a self-enforcing constraint on supply—but also in how its incentive structure drives the mining community to improve the bitcoin ecosystem. Since miners are compensated for their efforts in bitcoins, their interests are closely aligned with how the international market of potential bitcoin

155. Anyone can access the blockchain and even search the database through many widely available websites that keep a complete record. See, e.g., BLOCKCHAIN, https://blockchain.info [https://perma.cc/2LQY-ACG4].

156. As of 2006 , the government estimated that there could be as much as $\$ 200$ million in counterfeit circulation. U.S. TREASURY DeP'T, ThE UsE AND COUNTERFEITING OF UNITED StATES CURRENCY ABROAD, PART 3, at 70 (2006), https://www.federalreserve.gov /boarddocs/rptcongress/counterfeit/counterfeit2006.pdf [https://perma.cc/QH45-3WVH].

157. Böhme et al., supra note 57, at 219. 
users values bitcoin. Because of this incentive structure, profit-maximizing miners will always seek the solution that maximizes the value of bitcoin. ${ }^{158}$

Bitcoin's supply is fixed. Accordingly, for it to become in any way significant to the global economy, two things must happen: (1) the price of bitcoin must continue to grow, and (2) it must become a more stable store of value in order for individuals to adopt it as a currency. ${ }^{159}$ Thus, the interests of bitcoin's mining community and its ability to respond to the demands of the market are closely aligned with the success of bitcoin as a currency. As Part III will explore, the interplay of this dynamic is complex, and the opportunity for bitcoin to grow relies in no small part on the failure of certain governments to provide their citizens with a form of currency they can trust to maintain value. The freedom of bitcoin's miners to solve issues organically represents a historic moment into witnessing how nonlegal mechanisms, made possible by developments in computational technology, can supplement and even displace a traditional governmental function.

\section{AdVANTAGES AND DisAdVANTAGES OF BITCOIN}

While Part II explored how bitcoin's mechanics achieve order for currency without a law of currency, this Part examines the benefits and costs of a monetary regime outside of state influence. It explains why order without law in currency may offer greater liberty to individuals in their dealings with others, while also acting as a check against bad political actors. This Part then addresses the most important critiques of bitcoin's potential. It ends by sketching a picture of the world with bitcoin as a widely accepted and globally used currency.

\section{A. Advantages of Order Without Law in Currency}

Bitcoin offers an alternative to state-issued fiat, providing salutary competition to monetarily oppressive regimes. Its decentralized nature also enables functionality that traditional banking products do not offer. Just as competition in Scottish banking systems enabled financial product innovation in the eighteenth century, bitcoin may become a source for innovation in the legal and financial sectors. As more people use bitcoin, its price will likely stabilize, making it a competitor to less oppressive monetary regimes established under law, like those in developed nations.

\section{Competition to State-Issued Currencies}

In developing countries, domestic currency typically derives its value directly from its exchange rate with the U.S. dollar - a rate often set directly by the central bank of that nation. ${ }^{160}$ However, central banks in these regimes are often incapable

158. See Chris Pacia, Bitcoin Mining Explained Like You're Five: Part 1 - Incentives, ESCAPE VELOCITY (Sept. 2, 2013), https://chrispacia.wordpress.com/2013/09/02/bitcoinmining-explained-like-youre-five-part-1-incentives [https://perma.cc/S9SA-5MWN] (explaining the incentive structure behind bitcoin's "proof of work" protocol).

159. These two requirements may seem in tension with one another. This tension is explored more in depth in Part III.

160. Lawrence H. White \& George Selgin, Why Private Banks and Not Central Banks 
of making the precommitments necessary to encourage individuals to transact in their currency. ${ }^{161}$ While the threat of legal and marketplace sanctions may encourage banks to honor their commitments, a nation's sovereign immunity shields it from the same market-driven pressures. ${ }^{162}$ In addition, political pressures to provide near-term economic boon can tempt central bankers into goosing the economy by way of the printers - a strategy that ultimately leads to devaluation of its own notes. ${ }^{163}$ Other governments impose currency controls that force the exchange of the nation's currency at a rate above what they could command on an open currency exchange. ${ }^{164}$ In these circumstances, citizens have little trust in the currency of the nation and would readily consider alternative currencies.

Bitcoin's greatest advantage over such state-issued currencies is that it has no political master to serve. Bitcoin grants an option to citizens of monetarily oppressive regimes to transact in something other than their state-issued currencies. In fact, bitcoin has gained significant market share in transactions in nations such as Cyprus, ${ }^{165}$ Argentina, ${ }^{166}$ and China, ${ }^{167}$ where citizens have reason to doubt the value of the national currency.

For instance, bitcoin use in Argentina doubled between 2014 and 2015 when government action undermined the national currency. ${ }^{168}$ In Buenos Aires, there are roughly 150 venues that accept bitcoin, compared to 90 in London and 87 in New York City. ${ }^{169}$ Entrepreneurs in Argentina are offering individuals and businesses the ability to circumnavigate the country's stringent currency regulations by starting up bitcoin exchanges and services. ${ }^{170}$ This activity has had influence on the economic platforms of Argentinian politicians. ${ }^{171}$ Argentina's current reformist president, Mauricio Macri, was the first politician in Argentina to organize a forum on

Should Issue Currency, Especially in Less Developed Countries, LIBRARY ECON. \& LIBERTY (Apr. 19, 2000), http://www.econlib.org/library/Features/feature3.html [https://perma .cc/LD84-BEP2].

161. Id.

162. Id.

163. Id.

164. See Morris Goldstein \& Philip Turner, Controlling Currency Mismatches in EMERGING MARKETS 63-76 (2004).

165. Ian Jackson, Bitcoin Around the World: Cyprus, Inside Bitcoins (Jan. 21, 2015), http://insidebitcoins.com/news/bitcoin-around-the-world-cyprus/29026 [https://perma.cc /4RBB-CEM5].

166. Tom Jeffreys, Can Bitcoin Save Argentina 's Flailing Economy?, DIGG (Jan. 15, 2016, 12:42 PM), http://digg.com/2016/argentina-bitcoin [https://perma.cc/M6SQ-RVQS].

167. Why the Chinese Dominate Bitcoin Trading, VALUEWALK (May 8, 2016, 9:10 PM), http://www.valuewalk.com/2016/05/chinese-dominate-bitcoin-trading [https://perma.cc /XZ8Y-36DF].

168. Jeffreys, supra note 166. As one journalist notes, "Argentina has made a name for itself as a country where [b]itcoin is widely accepted to buy real, everyday items." Will Ellis, What Argentina and the U.S. Can Teach Us About Bitcoin Adoption and Regulation, PANAM Post (Oct. 26, 2017), https://panampost.com/editor/2017/10/26/bitcoin-adoption-and -regulation [https://perma.cc/ZW9N-WMZC].

169. Jeffreys, supra note 166.

170. Id.

171. Id. 
bitcoin. ${ }^{172}$ His "Minister of Modernization" delivered the opening speech at the convention. ${ }^{173}$

While one might expect monetarily oppressive regimes to try to shut down bitcoin, it does not appear to be nearly as susceptible to the public law intervention that brought down private law banking. For instance, China attempted to destroy the viability of bitcoin as a payment system within its nation. In December of 2013, with Chinese demand driving bitcoin well over $\$ 1000$, the People's Bank of China banned Chinese financial institutions and payments companies from pricing, buying or selling bitcoin, or insuring bitcoin-linked products. ${ }^{174}$ The Chinese central bank then doubled down on its bitcoin prohibitive legislation in April of 2014, ordering commercial banks and payment companies to close all bitcoin-related trading accounts. ${ }^{175}$ As seen in Figure 2, these legislative measures had significant impact on bitcoin's trading value.

FiguRe 2. BitCoin Price FluCtUATION (OCT. 2013-JULy 2014)

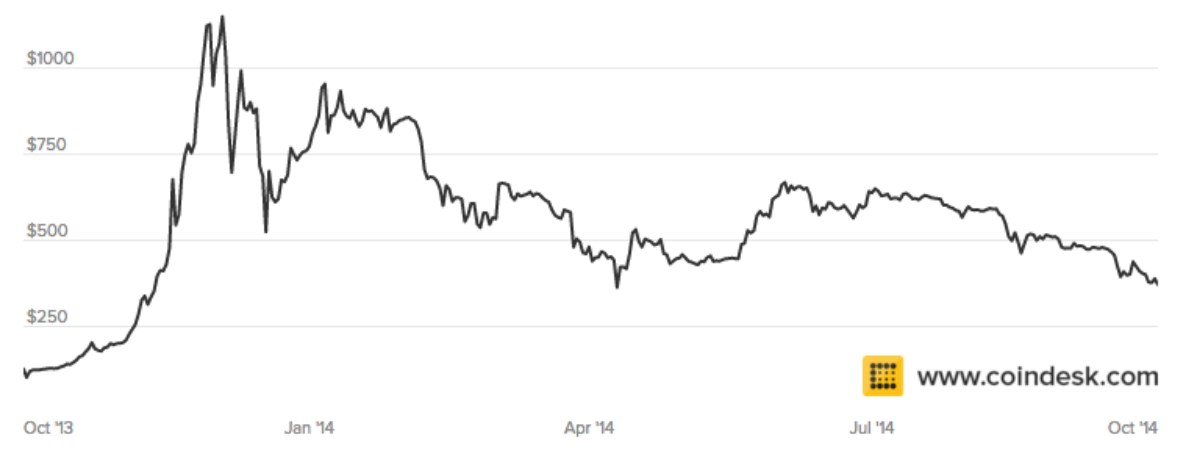

But after the initial market shock, bitcoin use has been rapidly increasing in China. Usage, acceptance, and awareness of bitcoin significantly increased in China from 2015 through 2016, causing the price of bitcoin to enjoy steady increases.

China's attack on bitcoin has failed because individuals were still able to use the internet to buy and exchange bitcoin, given the ubiquity of the internet and bitcoin's censorship-resistant nature. Moreover, the restrictions on China's currency that make bitcoin relatively attractive to its people have not subsided. For instance, China

172. Julio Gil-Pulgar, Argentina's New President Might Just Be a Bitcoin Supporter, BITCOIN NEws (Dec. 13, 2015), https://news.bitcoin.com/argentinas-new-president-mightjust-bitcoin-supporter [https://perma.cc/HJ84-6DKN].

173. Id.

174. Alec Liu, China Just Popped the Bitcoin Bubble, ViCE: MotherboARD (Dec. 18, 2013, 8:15 AM), https://motherboard.vice.com/en_us/article/wnjqpq/china-just-popped-thebitcoin-bubble [https://perma.cc/LC8X-CL77].

175. Chao Deng \& Lingling Wei, China Cracks Down on Bitcoin, Wall St. J. (Apr. 1, 2014, 10:15 AM), http://www.wsj.com/articles/SB100014240527023041572045794 75233879506454 [https://perma.cc/G3PR-BDKT].

176. Bitcoin Price Index Chart, CoINDESK, http://www.coindesk.com/price. 
enforces strict capital controls - allowing individuals to remove at most $\$ 50,000$ out of Chinese banks - and is looking to resort to increasingly restrictive administrative measures to quell capital outflows that have sparked in response to the downturn in the Chinese economy. ${ }^{177}$ Citizens in China who purchase bitcoin are able to escape these capital controls, as transfer of bitcoins can be instantaneously made to anywhere in the world without reliance on a third-party financial institution. ${ }^{178}$ In May 2016, over ninety percent of bitcoin currency exchanges were still taking place in yuan denominations. ${ }^{179}$

Bitcoin is most competitive against the national currencies that are most restricted or most unstable. Currently, as discussed below, the value of bitcoin is itself relatively unstable. Thus, it cannot yet successfully compete against more established and stable currencies. But, as we will discuss in Part IV, bitcoin has a path to become more generally competitive, as it gains market share and value in competition with the currency of monetarily oppressive regimes.

\section{Access for the Underbanked}

Many people in the world are underbanked. Two billion people, or roughly thirty percent of the global population, do not have access to a bank account. ${ }^{180}$ These people are mostly in developing nations, but even in developed nations, many people lack bank accounts. These unbanked individuals also represent a huge opportunity for bitcoin.

While brick-and-mortar financial institutions have not reached these individuals, in large part because of bad government regulations, ${ }^{181}$ another aspect of the computational revolution - the rapid growth of smartphone use - is enabling these individuals to connect to the internet and thus to bitcoin. In fact, by 2020, it is projected that eighty percent of adults on earth will have their own smartphone. ${ }^{182}$ These conditions are enabling entrepreneurs and venture capitalists to leverage bitcoin to serve those without immediate access to a global financial system. Anyone

177. Lilian Karunungan, China Will Probably Tighten Capital Controls, SocGen Says, BloOMBerg (Feb. 1, 2016, 11:01 PM), http://www.bloomberg.com/news/articles/2016-02 -02/china-will-probably-have-to-impose-capital-controls-socgen-says [https://perma.cc 159KF-3N87].

178. China Exchanges Weigh in on Bitcoin Capital Controls, CoIn News AsIa (Jan. 25, 2016), http://www.coinnewsasia.com/china-exchanges-weigh-in-on-bitcoin-capital-controls [https://perma.cc/XQ7G-KMAC].

179. Exchange Volume Distribution, BITCOINCHARTS, http://bitcoincharts.com/charts /volumepie [https://perma.cc/P6NZ-LE4L].

180. Karen Weise, Why Half the World Doesn't Have Bank Accounts, Bloomberg (Apr. 25, 2012, 1:40 PM), http://www.bloomberg.com/news/articles/2012-04-25/why-half-the -world-doesnt-have-bank-accounts [https://perma.cc/KRC4-ZC7H].

181. Government regulations create burdensome prerequisites for opening a bank account. In places like Latin America, many complain that institutions require too much documentation. See id. Moreover, governments place hurdles on individuals who wish to send money across borders to their families back home. Id.

182. Benedict Evans, Mobile Is Eating the World, SLIDEShare (Oct. 28, 2014), http://www.slideshare.net/a16z/mobile-is-eating-the-world-40841467 [https://perma.cc /MGS8-U62Y]. 
with access to the internet can hold his or her own bitcoin and make global payments, essentially becoming their own bank. To illustrate bitcoin's potential to serve the underbanked, this section will look at two problems typically faced by the underbanked: (1) liquidity and (2) access to credit.

Bitcoin can enable greater liquidity among the underbanked. People lacking access to traditional bank accounts spent $\$ 2.1$ billion in 2016 on check cashing services alone. ${ }^{183}$ Bitcoin can enable these consumers to receive funds sent by peers, employers, or lenders in digital wallets within minutes. Bitcoin users can then deploy these funds to pay bills and send money to family members with minimal transaction costs. In fact, bitcoin ATMs have recently become a popular means for the unbanked to gain access to something akin to a bank account. ${ }^{184}$

Cryptocurrencies can also enable the underbanked to gain access to affordable credit. Typically, low income individuals often struggle to establish credit history, as the majority of their transactions take place in cash. Because cryptocurrencies have common, public ledgers that log all transactions, they can offer lenders a clear view into an individual's payment history as revealed by a public wallet address. Companies such as BitPagos offer their customers in Argentina access to credit. ${ }^{185}$ Users can borrow bitcoin directly from the service, with credit extended based on the user's annual salary. ${ }^{186}$ Users can then pay back the loan in three- or six-month installments, plus interest. This system requires no credit card, bank account, or account maintenance fees.

For bitcoin to realize its potential for the underbanked, it still faces some hurdles. Most of the world's poor deal in cash, and choosing bitcoin as a store of value is risky for those who know very little about the digital asset and few assets overall.

Companies, like Abra, are attempting to solve this issue by building solutions that shield users from the complexities of bitcoin. ${ }^{187}$ When an Abra user opens his account on his smartphone, they see the current value of his or her bitcoin account denominated in local currency. ${ }^{188}$ For this amount to remain stable even as the price

183. Eric Wilson \& Eva Wolkowitz, Ctr. For Fin. Servs. Innovation, 2017 FinANCIALly UNDERSERVED MARKET Size StUdy 15 (2017), https://s3.amazonaws.com/cfsi -innovation-files-2018/wp-content/uploads/2017/04/27001546/2017-Market-Size-Report _FINAL_4.pdf [https://perma.cc/LQ62-6RHL].

184. Justin O'Connell, Bitcoin ATMs Are Popular with the Unbanked, but the Regulatory Future Is Unclear, VicE: MOTHERBOARD (May 30, 2016, 7:00 AM), https://motherboard.vice .com/en_us/article/ezppkp/bitcoin-atms-unbanked-regulation [https://perma.cc/P9AU -AWWB].

185. Pete Rizzo, Bitcoin Wallet Startup Now Extending Credit to Users, CoINDESK (Apr. 5, 2016, 4:30 PM), http://www.coindesk.com/bitpagos-bitcoin-wallet-credit [https://perma .cc/7GQS-5CVT].

186. Id.

187. Growth of startups like Abra has been increasing exponentially worldwide. After a slow start, bitcoin adoption and awareness in India has been growing exponentially, with bitcoin banking platform Zebpay adding over 20,000 new users per month. Diana Ngo, India's Zebpay Adds 20,000 New Users Monthly, Looks to “Expand More Aggressively," NASDAQ (Sept. 5, 2016, 4:17 PM), http://www.nasdaq.com/article/indias-zebpay-adds-20000-newusers-monthly-looks-to-expand-more-aggressively-cm674710\#ixzz4K2Qtutyj [https:// perma.cc/WXS4-Z8CP].

188. Abra Hechnology: How It Works, ABRA, 
of bitcoin goes up and down, Abra sells the risk of price fluctuation to third-party speculators through a maneuver that resembles hedging in the commodity and options markets. ${ }^{189}$ Much like the evolution of the internet over the past few decades, Abra is simplifying a computationally complex product to reach a broader user base among the less tech-savvy.

\section{Smart Contracts}

Bitcoin, and other emerging cryptocurrencies, can also enable smart contracts. A smart contract is a program that verifies and enforces the negotiation or performance of a contract. ${ }^{190}$ Instead of relying on enforcement through law, smart contracts can be self-executing and self-enforcing, which reduces the transaction costs associated with traditional contracting. ${ }^{191}$ It is an example of how the order without law that is bitcoin can project a nonlegal order into other areas now governed by law.

To illustrate the functionality of a smart contract, consider a simple transaction where two people wish to enter a hedging contract. Imagine that these two people each want to put up $\$ 1000$ worth of bitcoin, and execute a contract so that after a month, one of the individuals would receive back $\$ 1000$ worth of bitcoin at whatever the dollar exchange rate happens to be, while the other would receive the rest of the bitcoin - which may or may not end up being worth more than it was at the beginning of the month. A smart contract would enable them to submit the bitcoin to a secure destination, and then automatically distribute the bitcoin at the end of the term without any third-party action.

Typically, disputes about the terms of trade and external conditions triggering the trade are settled through whatever private law system governs. ${ }^{192}$ With a smart contract, there is only one determinate set of trade terms, written in computer code. ${ }^{193}$ External conditions - like the price of oil or the cost of Google stock - can be fed in via a mutually agreed upon source. ${ }^{194}$ The contract then lives on the bitcoin blockchain and will execute when an event happens or the terms of the contract expire. ${ }^{195}$ Thus, bitcoin's functionality allows such contracts to be executed wholly

https://web.archive.org/web/20170126085725/https://www.goabra.com/technology [https:// perma.cc/AZ9Y-Q8NL] (describing Abra's operation).

189. Id.

190. Chris DeRose, 'Smart Contracts' Are the Future of Blockchain, AM. BANKER (Jan. 8, 2016, 9:30 AM), http://www.americanbanker.com/bankthink/smart-contracts-are-the-future -of-blockchain-1078705-1.html [https://perma.cc/RMH8-ZL8C].

191. Id.

192. Depending on which jurisdiction governs the dispute, resolving these disputes can prove very costly. See WORLD BANK \& INT'L Fin. CORP., DOING Business 2008, at 50 (2007), http://www.doingbusiness.org/content/dam/doingBusiness/media/Annual-Reports/English /DB08-FullReport.pdf [https://perma.cc/A25K-MHXC].

193. Trevor I. Kiviat, Beyond Bitcoin: Issues in Regulating Blockchain Transactions, 65 DUKE L.J. 569, 605-06 (2015).

194. Id.

195. Nick Vogel, The Great Decentralization: How Web 3.0 Will Weaken Copyrights, 15 J. Marshall ReV. InTELl. Prop. L. 136, 141 (2015). 
with software and with no reliance on law, thus avoiding any issues with the friction and reliability of the legal system. ${ }^{196}$

This functionality is quite different from the decision to execute contracts through banks, even when bank accounts enable automatic payments. First, even with automatic payments the bank has control over the execution of the contract features. As the ultimate guardian of the bank account, a bank can stop payments. ${ }^{197}$ The smart contract enabled by bitcoin is automatic. In a bitcoin ecosystem, there is no single source of control. ${ }^{198}$ With smart contracts running on a blockchain, the logic is run in parallel as bitcoin miners validate transactions, and the results are compared and confirmed via bitcoin's distributed consensus. ${ }^{199}$

Second, smart contracts are completely transparent, unlike payments mediated by the bank. ${ }^{200}$ This means that anyone can view a smart contract, and if he likes the logic, he can choose to use it. There can be off-the-shelf contracts for general use, like the hedging example illustrated previously, and more specific smart contracts for other needs. ${ }^{201}$

Most importantly, smart contracts through bitcoin are not constrained by the laws of any jurisdiction. Bitcoin affords two or more individuals complete freedom over the rules that govern their engagement, as the computer logic that executes the contract is indifferent to the political concerns of any government. While courts in the United States have the power to enjoin the actions of individuals who enter a contract under private law, a bitcoin transaction self-executes automatically.

Smart contracts also illustrate why bitcoin does not ultimately need legal tender rules by which the government requires its currency to be accepted. ${ }^{202}$ If it becomes

196. In many nations, enforcing contracts is both inefficient and cost prohibitive. While the most efficient legal regimes settle contract disputes in approximately half a year, enforcement in many nations can take well over three years. Additionally, the cost related to enforcement is on average at least $10 \%$ of the claim itself but reaches well over $100 \%$ in many developing nations. See WORLD BANK \& INT'L FIN. CORP., supra note 192, at 50.

197. Ronald J. Mann, Making Sense of Payments Policy in the Information Age, 93 Geo. L.J. 633, 663 (2005).

198. Kiviat, supra note 193, at 605.

199. Id. at 605-06.

200. Victor Li, Bitcoin's Useful Backbone: Blockchain Technology Gains Use in Business, Finance, and Contracts, A.B.A. J., Mar. 2016, at 31.

201. For example, Honduras is one of the first countries that has authorized blockchain to record real estate transactions. $I d$.

202. The United States enforces acceptance of U.S. coins and currency for "all debts, public charges, taxes, and dues" by operation of law. 31 U.S.C. $\$ 5103$ (2012). Accordingly, U.S. currency must be accepted as payment for any contract between individuals. The vast majority of nations have similar public tender laws, and as such, have the authority to alter these laws to serve political objectives. See, e.g., Lawrence H. Summers \& Natasha Sarin, India Just Made a Big Mistake with Its Currency Ban, WASH. Post (Nov. 22, 2016), https://www.washingtonpost.com/news/wonk/wp/2016/11/22/india-just-made-a-big-mistake -with-its-currency-ban [https://perma.cc/9RQS-HPKP] (noting that, in November 2016, India's Prime Minister announced that the 500 (\$7.50) and 1000 (\$15.00) rupee-equivalent to roughly eighty-five percent of the cash in circulation - would cease to be legal tender in a crackdown on fraud and tax evasion). 
a stable currency, software can execute agreements denominated in bitcoin without recourse to tender law.

While it is yet to be determined whether this form of order without law will be preferable to private law contract enforcement, bitcoin gives individuals a choice. As the user base of bitcoin grows, people can elect over a large range of contracts whether to contract under an order without law or under a legal regime. The market will determine which is superior.

\section{B. Criticisms of Bitcoin}

As bitcoin has gone mainstream, governments have inevitably sought to regulate it. The software underlying bitcoin does not provide a criminal code. It does not have built-in mechanisms to return bitcoins stolen by fraud, let alone the ability to imprison the perpetrators. Bitcoin does not collect any taxes from its users, nor does it set rules about what types of transactions its users can engage in.

Governments therefore may regulate the conduct of its citizens and businesses who wish to transact in bitcoin. ${ }^{203}$ These regulatory regimes can exist while leaving the essence of bitcoin as an order without law. Order without law in a monetary system such as bitcoin requires independence only in the rules governing money supply. Unlike any of its private or public law predecessors, bitcoin guarantees its users an unprecedented level of trust that the value of the currency will not be manipulated to serve any political interests. While governments may choose to regulate the use of bitcoin and other cryptocurrencies, the algorithm that governs the supply of bitcoin is resistant to government capture. Governments will undoubtedly seek to tax its use, ${ }^{204}$ impose anti-money laundering regulations on its deployment, ${ }^{205}$ and criminally prosecute those who use bitcoin for nefarious uses. ${ }^{206}$ While some of these regulations may be less desirable than others when it comes to fostering the growth and adoption of bitcoin, none of them threaten the decentralized trust upon which bitcoin's order without law rests or replaces its fundamental order with a law of currency.

203. See Kiviat, supra note 193 (analyzing the regulatory patchwork that has begun to form around virtual currencies); Max I. Raskin, Realm of the Coin: Bitcoin and Civil Procedure, 20 FORDHAM J. CORP. \& FIN. L. 969 (2015) (arguing that bitcoins ought to be treated as tangible property for jurisdictional purposes so that courts may apply existing due process and comity jurisprudence).

204. Currently, the IRS treats bitcoin as property, not currency, for U.S. federal tax purposes. See IRS Virtual Currency Guidance: Virtual Currency Is Treated as Property for U.S. Federal Tax Purposes; General Rules for Property Transactions Apply, IRS (Mar. 25, 2014), https://www.irs.gov/uac/newsroom/irs-virtual-currency-guidance [https://perma.cc /3PCS-Z8TM].

205. In July 2016, the executive branch of the European Union advised that wallet providers be brought under the scope of its anti-money laundering and countering terrorist financing regulations. See Jacek Czarnecki, No, the EBA's Bitcoin Regulation Proposals Aren't All Bad, CoINDesk (Aug. 19, 2016, 1:05 PM), https://www.coindesk.com/defense -ebas-proposed-bitcoin-regulation [https://perma.cc/JC97-EKQS].

206. See, e.g., reminesjoseph, Three Men from Ireland to Stand Trial for Dealing Drugs Online, MERKLE (Aug. 17, 2016), http://themerkle.com/three-men-from-ireland-to-stand -trial-for-dealing-drugs-online [https://perma.cc/36RC-TVKC]. 


\section{Crime and Fraud in Bitcoin}

In 2010, Mt. Gox was started as one of the first bitcoin exchanges in the worlda place where an individual could exchange euros and dollars for bitcoin. ${ }^{207}$ By 2013 , it was responsible for up to $80 \%$ of all bitcoin trading volume. ${ }^{208}$ And by February of 2014, Mt. Gox had suspended bitcoin trading and announced that 750,000 bitcoins were missing and likely stolen - an amount that was valued at more than $\$ 350$ million at the time. ${ }^{209}$ On March 9, 2014, Mt. Gox filed for bankruptcy in the United States to temporarily halt legal action by traders who alleged the operation was a fraud. ${ }^{210}$ Bitcoin experts and law enforcement have spent over two years trying to figure out how hundreds of thousands of bitcoins disappeared from the exchange overnight.

More recently, on August 2, 2016, Bitfinex-a Hong Kong-based cryptocurrency exchange - became the latest to declare itself a victim of a major security breach. Private bitcoin wallets were hacked and consumer funds were stolen, awakening the ghost of the Mt. Gox debacle. ${ }^{211}$ In total, Bitfinex lost approximately $\$ 66$ million worth of bitcoin, or roughly about $18 \%$ of what was lost during the Mt. Gox heist. ${ }^{212}$ And like the Mt. Gox downfall, the Bitifinex hack had a significant impact on the price of bitcoin, tumbling as much as $20 \%$ as the hack shook the public's trust in bitcoin. ${ }^{213}$

At first glance, the failures at Mt. Gox and Bitfinex seem to highlight a need for greater consumer protection when dealing with bitcoin wallet providers. Services such as Mt. Gox and Bitfinex, that offer individuals a user-friendly interface to engage in bitcoin transactions, seem to be susceptible to fraudulent attacks. In the wake of both incidents, regulators and politicians have been quick to blame the decentralized nature of bitcoin for the loss of consumer assets.

But the problem with Mt. Gox and Bitfinex did not lie with bitcoin, but with companies whose business is holding bitcoin. First, the Mt. Gox and Bitfinex hacks do not reflect on the security of the bitcoin network. The bitcoin network itself has never been hacked. ${ }^{214}$ Second, the ordinary processes of criminal law may be used to

207. Robert McMillan, The Inside Story of Mt. Gox, Bitcoin's $\$ 460$ Million Disaster, WIRED (Mar. 3, 2014, 6:30 AM), https://www.wired.com/2014/03/bitcoin-exchange [https://perma.cc/M28G-NFC9].

208. Lawrence Trautman, Virtual Currencies: Bitcoin \& What Now After Liberty Reserve, Silk Road, and Mt. Gox?, 20 Rich. J. L. \& Tech. 1, 101 (2014); Yessi Bello Perez, Mt. Gox, The History of a Failed Bitcoin Exchange, CoINDESK (Aug. 4, 2015, 6:46 PM), https://www.coindesk.com/mt-gox-the-history-of-a-failed-bitcoin-exchange [https://perma.cc /877C-KCCW].

209. Trautman, supra note 208; Perez, supra note 208.

210. McMillan, supra note 207.

211. Stan Higgins, The Bitfinex Bitcoin Hack: What We Know (and Don't Know), COINDESK (Aug. 3, 2016, 6:49 PM), http://www.coindesk.com/bitfinex-bitcoin-hack-know -dont-know [https://perma.cc/YP9G-WVGK].

212. Id.

213. $I d$.

214. In the history of bitcoin, there has never been an attack on the blockchain that resulted in stolen money. Neither has there ever been a reported theft resulting directly from a vulnerability in the original bitcoin client, or a vulnerability in the protocol itself. Bitcoin is 
reinforce bitcoin's order without currency law. Those responsible for hacking Mt. Gox and Bitfinex may be prosecuted.

Moreover, in the wake of the Mt. Gox collapse, a wide variety of startups began to hold bitcoins for their parties, with established entrepreneurs and venture capitalists getting involved. ${ }^{215}$ Thus, the basic laws of crime and property together with market innovation can reinforce the basic order without law that is bitcoin.

Bitcoin has also been criticized because of its connection to criminal activity. The most infamous example of this illicit use was Silk Road, an online black market best known as a platform for selling drugs. Silk Road was enabled, in part, through the anonymous transfer of value through bitcoin. By the end of 2013, it was estimated that approximately $\$ 1.2$ billion worth of trades had been facilitated by the underground network. ${ }^{216}$ Here, again, the ordinary process of law intervened. The mastermind of Silk Road was arrested and sentenced to life in prison, creating a large deterrent to such activities. ${ }^{217}$ Thus, it is important to acknowledge that while bitcoin works without a law of currency, its overall utility is still dependent on other orders that are rooted in law. As a result, bitcoin no less than other innovations is dependent on the neutral and fair legal regulation of the ecosystem that inevitably grows up to surround an innovation.

\section{Bitcoin's Governance}

One of the core characteristics of bitcoin, its governance model, has drawn significant criticism. Compared with conventional payment systems, bitcoin lacks a governance structure other than its underlying software. This has several implications for the functioning of the system. First, bitcoin payments are irreversible in that the protocol provides no way for a payer to reverse an accidental or unwanted purchase, whereas other payment platforms, such as credit cards, do include such procedures. ${ }^{218}$ These design decisions are intentional-simplifying the bitcoin platform and reducing the need for central arbiters. While it may have a cost, the

secured by standard cryptographic functions. These functions have been peer reviewed by cryptography experts and are considered unlikely to be breakable in the foreseeable future. Is Bitcoin Secure? Has the Bitcoin Network Ever Been Hacked?, CoInBASE, https://support.coinbase.com/customer/en/portal/articles/1836669-is-bitcoin-secure-has-the -bitcoin-network-ever-been-hacked- [https://perma.cc/42V2-4QXV].

215. Nathaniel Popper, Mt. Gox Creditors Seeks Trillions Where There Are Only Millions, N.Y. TIMES: DeAlBooK (May 25, 2016), http://www.nytimes.com/2016/05/26/business /dealbook/mt-gox-creditors-seek-trillions-where-there-are-only-millions.html [https://perma .cc/22QA-BZL3].

216. Willard Foxton, If Silk Road Was a Legitimate Startup, It Would Be Worth $\sim \$ 2.4$ Billion, Bus. INSIDER (Oct. 4, 2013, 8:37 AM), http://www.businessinsider.com/silk-road -valuation-worth-2-or-3-billion-2013-10 [https://perma.cc/A9JM-T4N8].

217. Andy Greenberg, Silk Road Creator Ross Ulbricht Loses His Life Sentence Appeal, WIRED (May 31, 2017, 1:12 PM), https://www.wired.com/2017/05/silk-road-creator-ross -ulbricht-loses-life-sentence-appeal [https://perma.cc/R94E-FCZK].

218. Adhil Shetty, Driven by Demonetisation, Bitcoin Hits \$1000: Should Indians Buy It?, FIN. EXPRESS (Jan. 16, 2017, 7:20 PM), http://www.financialexpress.com/money/driven-by -demonetisation-bitcoin-hits-1000-should-indians-buy-it/510084 [https://perma.cc/V89H -8D4D]. 
payment system competes with others that do not have this feature and the market will decide when one payment system is used in preference to others.

But the more fundamental criticism of bitcoin's governance model lies in the mechanisms required to update the network. ${ }^{219}$ The blockchain is decentralized, which means there is no absolutely "correct" chain. Any miner wishing to take part in the economic incentives of the bitcoin network downloads the accepted version of the blockchain, verifies new transactions against the laws of math and bitcoin, and chooses the correct chain accordingly. Every so often there is disagreement in the network as to how a miner "validated" a transaction. Miners tend to quickly converge to an accepted solution because of the profit-related motives in ensuring a consensus. ${ }^{220}$

Like any piece of software, sometimes change is needed to meet some type of technical demand. For most of its history, bitcoin has benefited from a group of core developers who have contributed and volunteered time to work on the bitcoin code. ${ }^{221}$ Since bitcoin is not under their control, miners must each individually adopt any updates for the desired changes to take effect. For most of the history of bitcoin, these changes have been relatively uncontroversial and universally adopted by the mining community. 222

But from 2015 to August 2017, bitcoin's mining community faced the most deeply contested debate concerning its future development, which was dubbed the "forking hell." ${ }^{223}$ Under the previous version of the software, the bitcoin network could handle only about 350,000 transactions per day. At bitcoin's inception, this limit was hardly seen as a constraint, but as Figure 3 shows, the network is fast approaching this upper limit.

219. To illustrate this concern, contrast bitcoin with the iPhone. When an issue in a model of iPhone arises, a group of developers at Apple fix that issue, and then a group of executives decide when the update is released to the public. Bitcoin lacks this hierarchy. When an issue arises in bitcoin, many groups of developers set out to fix the issue. With small issues, these many groups often reach consensus on how to implement a fix. But with more controversial updates, disagreement sometimes occurs. As this Section explores, bitcoin miners - driven by the demands of the market - are the drivers behind bitcoin's governance model.

220. The profit motive behind this again comes down to the cost of computing power. If a miner disagrees about the consensus reached by the other miners and wants to advocate for his version of the blockchain, he must divert his computational resources away from the consensus blockchain, missing the opportunity to compete for newly minted bitcoins.

221. The "Bitcoin Core" team is largely considered the most talented bitcoin development team in the world. See Joseph Young, Bitcoin Core Is Most Talented Dev Team, Says VC, COINTELEGRAPH (Nov. 3, 2016), https://cointelegraph.com/news/bitcoin-core-is-most -talented-dev-team-says-vc [https://perma.cc/9CZX-WKXL]. The number of bitcoin developers has grown rapidly, from roughly only a handful in 2011, up to roughly 5000 in 2016. Id.

222. In fact, there have been almost forty updates to the bitcoin network since 2011 that have been universally adopted. See Bitcoin Core Version History, BitcoinCone, https://bitcoin.org/en/version-history [https://perma.cc/TTD6-9W2F].

223. Forking Hell, ECONOMIST (Aug. 22, 2015), http://www.economist.com /news/business-and-finance/21661404-spat-between-developers-may-split-digital-currency -forking-hell [https://perma.cc/2YZK-46ZJ]. 
FIGURE 3. NUMBER OF BITCOIN TRANSACTIONS PER DAY

(FEB. 2016-FEB. 2017) 224

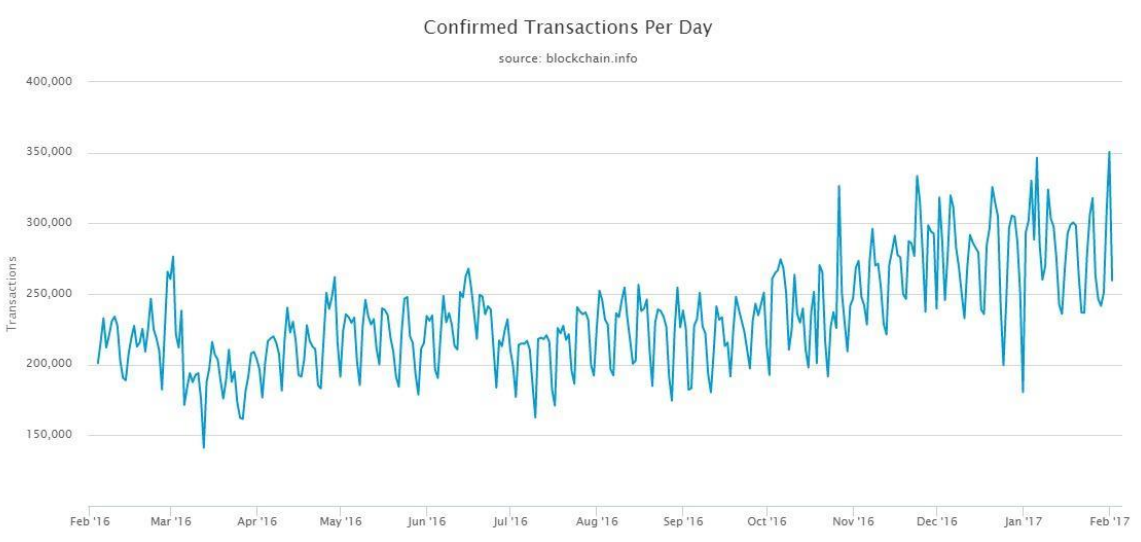

The solution to increasing the number of transactions the bitcoin network can handle in a given day is, from a technical perspective, relatively straightforward. ${ }^{225}$ Essentially, all that needs to be done is to change the amount of transactions processed in each "block" - the bundle of transactions that miners gather every ten minutes - to something that would allow miners to meet future demand. ${ }^{226}$ However, the question of how much to increase the threshold has economic effects. ${ }^{227}$ Any increase in the threshold would increase the requisite computing power necessary for an individual to keep a complete record of all transactions being added to the blockchain, which could result in a consolidation in the individuals capable of meeting these requirements. ${ }^{228}$ The disagreement drove a schism between those who seek to expand bitcoin's global adoption with those who desire that bitcoin remain as decentralized as possible. ${ }^{229}$ Many thought an actual fork between these two factions would be fatal to the bitcoin experiment. ${ }^{230}$

224. Confirmed Transactions per Day, BLOCKCHAIN, https://blockchain.info/charts/ntransactions?timespan=all\&showDataPoints=false \&daysAverageString=1\&show_header=tr ue \&scale $=0 \&$ address $=[$ https://perma.cc/AG9C-CLH7] .

225. Block Size Limit Controversy, BITCOIN WIKI, https://en.bitcoin.it/wiki/Block _size_limit_controversy [https://perma.cc/6TEF-T6H8].

226. $I d$.

227. Id.

228. $I d$.

229. Id.

230. See, e.g., Cade Metz, A Plan to Save Blockchain Democracy from Bitcoin's Civil War, WIRED (Mar. 29, 2017, 7:00 AM), https://www.wired.com/2017/03/plan-save-blockchain -democracy-bitcoins-civil-war [https://perma.cc/278A-3S8P] (stating that "the decentralized nature of [bitcoin] is a burden [to innovation]"). 
On August 1, 2017, this schism culminated into bitcoin forking into two separate cryptocurrencies: bitcoin and bitcoin cash. ${ }^{231}$ Each individual who owned bitcoin prior to the fork acquired equal parts bitcoin and bitcoin cash overnight, with each individual's balances reflected on the two new, independent blockchains. ${ }^{232}$ But bitcoin's fork coincided with a substantial rise in bitcoin's value - not its demise. In the months following the fork, bitcoin's price soared, and even after a significant correction in 2018, its price still dwarfs pre-fork levels. ${ }^{233}$

Indeed, the experience of this fork may suggest that permitting forks may have certain advantages. Forks may allow a cryptocurrency to create new currencies that are better optimized for different uses. In this case, bitcoin cash may be better suited to buying goods and services and bitcoin itself better suited to being held as an investment. Bitcoin cash more easily accommodates a greater number of transactions while bitcoin, with its more decentralized group of miners, might be thought less easy to manipulate.

Perhaps most importantly, forks permit the market to decide which qualities of a cryptocurrency they find the most valuable. In today's systems of modern centralized banking, individuals have no direct input into the rules that govern their nation's currency. However, bitcoin enables individuals to optimize its features to make it a more desirable currency, and then to test that desirability on a global level.

Historical mechanisms of order without law depend on tradition to bind a society, and these mechanisms can take generations to take effect. While it is ingrained in many to place their forks to the left of their plate, any coordinated effort to change this behavior would likely fail, even if it was discovered that there was some utility to having forks placed to the right of the plate. With bitcoin, rules are only programmed in software so long as society finds them desirable. If society ends up determining that bitcoin cash is much more desirable than bitcoin, individuals can simply choose to buy it instead.

In any event, for holders of the original bitcoin, the fork has been better than a stock split because the value of their combined holding is greater than before the fork. Ultimately, the market of cryptocurrency users will determine the relative value of bitcoin and bitcoin cash — a decision the market will make without influence from a centralized state authority.

\section{Competing Cryptocurrencies}

Critics argue that since there is minimal barrier of entry to creating a new cryptocurrency, bitcoin's value will eventually plummet as other cryptocurrencies enter the market and undercut the price of bitcoin relative to the dollar. ${ }^{234}$

These arguments flow from a flawed understanding of how bitcoin works. Unlike state-controlled currencies, such as the Chinese yuan or the Argentinian peso,

231. Gareth Jenkinson, Forks in the Road: 2017 Bitcoin Forks, CoINTELEGRAPH (Jan. 3, 2018), https://cointelegraph.com/news/forks-in-the-road-2017-bitcoin-forks [https://perma .cc/TZY8-SNNT].

232. $I d$.

233. See Market Price (USD), BlOCKCHAIN, https://blockchain.info/charts/market-price [https://perma.cc/FF9Q-C4J7].

234. See Cowen, supra note 119. 
cryptocurrencies are decentralized networks that have no price setting functionality. Bitcoin's exchange rate is determined exclusively by supply and demand, and thus, the network of buyers and sellers determine what bitcoin, or any other cryptocurrency, is worth. Even in the hypothetical where sophisticated actors, such as corporations or banks, create a cryptocurrency and fix a predetermined initial price that is a function of marketing costs as opposed to demand, it is likely there will be no buyers for these currencies. As the seventeenth century attempts by the British government to artificially fix interest rates prove, currency cannot be completely shielded from competitive effects.

Bitcoin has significant infrastructural advantages over other potential cryptocurrencies that are likely to maintain demand for it and weaken demand for competing currencies. First, bitcoin enjoys a sizable network effect over alternative cryptocurrencies. Most people who hear about digital currencies hear about them in the context of bitcoin. Additionally, any competing currency would likely face significant obstacles gaining adoption among merchants. Evidence of these types of network effects can be seen in other disruptive industries such as ridesharing. ${ }^{235} \mathrm{In}$ fact, with one exception, there have been no alternative cryptocurrencies that have seriously challenged bitcoin's throne as the dominant cryptocurrency. ${ }^{236}$

And at bitcoin's current stage, another currency is unlikely to have much effect on bitcoin price because any new cryptocurrency is likely to gain market share by displacing other currencies rather than bitcoin, given that bitcoin still has a small market share when compared to the global currency market. The rise of ethereum is a prime example of the room for growth in the economy of cryptocurrencies. Unlike bitcoin, which was primarily designed to serve as a currency for consumer payment transaction, the ethereum blockchain includes more features that appeal to the corporate world. ${ }^{237}$ And indeed, it has attracted quite significant attention, as corporate giants such as JPMorgan, Microsoft, and Intel Corporation are working together to build enterprise-level functionality on top of the ethereum blockchain. ${ }^{238}$

And while this activity has brought incredible growth to the price of ethereum, and many other cryptocurrencies, throughout 2017, bitcoin's price has grown

235. For example, although the technology underlying Uber is not difficult to duplicate, after six years in operation, its next closest competitor Lyft (founded only two years after Uber) has only three percent the reported revenue as Uber. See Heather Somerville, Lyft Executive Says on Track to Hit \$1 Billion in Gross Revenue, REUTERS (Nov. 17, 2015, 11:38 AM), https://ca.reuters.com/article/technologyNews/idCAKCN0T621K20151117 [https:// perma.cc/TEV5-U9QY].

236. Besides ethereum, the market capitalizations of all other cryptocurrencies have remained relatively stagnant. See Top 100 Cryptocurrencies by Market Capitalization, COINMARKETCAP, https://coinmarketcap.com [https://perma.cc/MK9T-2V44].

237. Yezi Peng, Will Ethereum Be the Platform that Successfully Brings Blockchain into the Mainstream?, HaRv. Bus. Sch. Digital Initiative (Feb. 26, 2017) https:// digital.hbs.edu/platforms-crowds/will-ethereum-platform-successfully-brings-blockchain -mainstream [https://perma.cc/3MMS-54G5].

238. Anna Irrera, JPMorgan, Microsoft, Intel and Others Form New Blockchain Alliance, REUTERS (Feb. 27, 2017, 5:53 PM), https://www.reuters.com/article/us-ethereum-enterprises -consortium/jpmorgan-microsoft-intel-and-others-form-new-blockchain-alliance-idUSKBN1 662K7 [https://perma.cc/H8NV-XM34]. 
significantly in tandem. ${ }^{239}$ What we are witnessing is the beginning of an "economy of cryptos." As different cryptocurrencies evolve to meet different market demands, individuals may acquire and trade between different cryptocurrencies, and in the process, rely less and less on the use of traditional fiat.

\section{Bitcoin Price Stability}

Perhaps the most critical precondition to widespread adoption of bitcoin as a means of exchange is price stability. As the CEO of Goldman Sachs put it, "[s]omething that moves up and down 20 percent in a day doesn't feel like a currency, doesn't feel like a store of value." ${ }^{240}$ Indeed, as demonstrated below, for most of bitcoin's history, it has behaved much more like a commodity than a currency.

\section{FigURE 4. BITCOIN VOLATILITY VS. OTHER COMMODITIES}

(JAN. 1, 2012-JUN. 29, 2019) 241

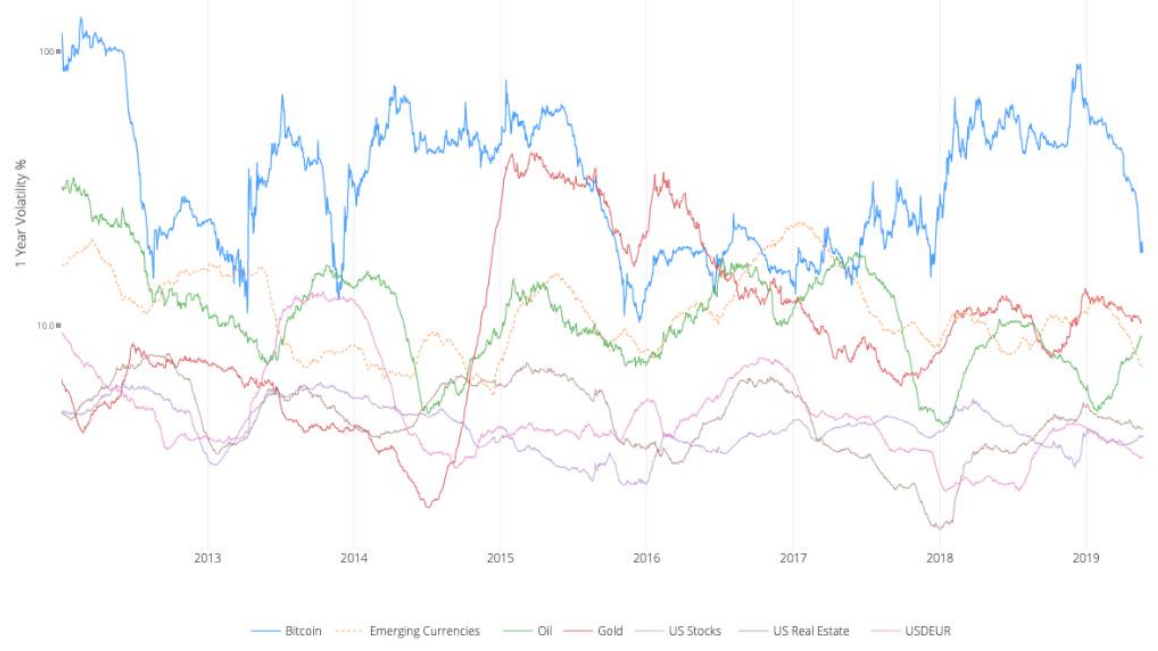

239. Interestingly, despite the significant price volatility bitcoin experienced throughout 2017 and 2018, it has proven to be far more resilient than other cryptocurrencies. While bitcoin's market cap dropped significantly from its 2017 peak, it actually gained ground against other cryptocurrencies in the process, and its market cap currently represents well over $50 \%$ of the overall cryptocurrency market. Top 100 Cryptocurrencies by Market Capitalization, supra note 236. Indeed, throughout the first half of 2019, bitcoin has nearly regained its 2018 losses while competing cryptocurrencies have lagged significantly behind.

240. Dakin Campbell, Blankfein Says It's Too Soon for a Bitcoin Strategy, BLoomberG (Nov. 30, 2017, 10:22 AM), https://www.bloomberg.com/news/articles/2017-11 -30/blankfein-says-too-soon-for-bitcoin-strategy-as-volatility-jumps [https://perma.cc/338R -Q6GJ].

241. Willy Woo, Bitcoin Volatility vs Other Assets, WoOBUll ChaRTs, http://charts.woobull.com/bitcoin-volatility-vs-other-assets [https://perma.cc/Z7QF-TA4X]. 
More recently, bitcoin experienced rapid price growth in 2017 due to a rush of new market entrants seeking to purchase bitcoin, before the market corrected and reached significantly lower levels of volatility in 2018 . While this demonstrates that bitcoin, like the internet, is subject to significant speculation in boom times, it does not represent some inherent flaw. History has demonstrated that technological innovations are typically followed by financial bubbles as markets take time to price innovation. ${ }^{242}$

Indeed, many commentators incorrectly conflate bitcoin's current volatility with some structural, underlying flaw in bitcoin itself. As discussed in Part IV, it is impossible to analyze bitcoin's volatility without the context that it is still a new asset class and without recognizing that the market around it is slowly maturing. It would be seemingly impossible for bitcoin adoption to grow anywhere near that of the U.S. dollar without short- to medium-term volatility. And volatility itself is not an intrinsic property of bitcoin, but rather a current reflection of its marketplace, which as discussed, can grow more sophisticated overtime.

Bitcoin's fixed supply-only 21 million will ever be created at a rate precommitted by lines of code-means that one side of its supply and demand curve is entirely predictable. What is far more complex, and more important to driving bitcoin's long-term pricing stability is its demand. Bitcoin faces a classic chicken and egg dilemma: for it to be an attractive currency, it needs to be a stable store of value, but for it to be a stable store of value, it needs to gain greater adoption as a currency.

Bitcoin's recent price swings certainly call into question its long-term capacity for acting as a store of value. Starting in 2017, bitcoin saw dramatic increases in its price, peaking at a value close to $\$ 20,000$ with a market cap well north of $\$ 300$ billion before retracing nearly $80 \%$ of its gains by the end of 2018 :

FIGURE 5. BITCOIN PRICE

(JAN. 1, 2017-JUN. 29, 2019) $)^{243}$

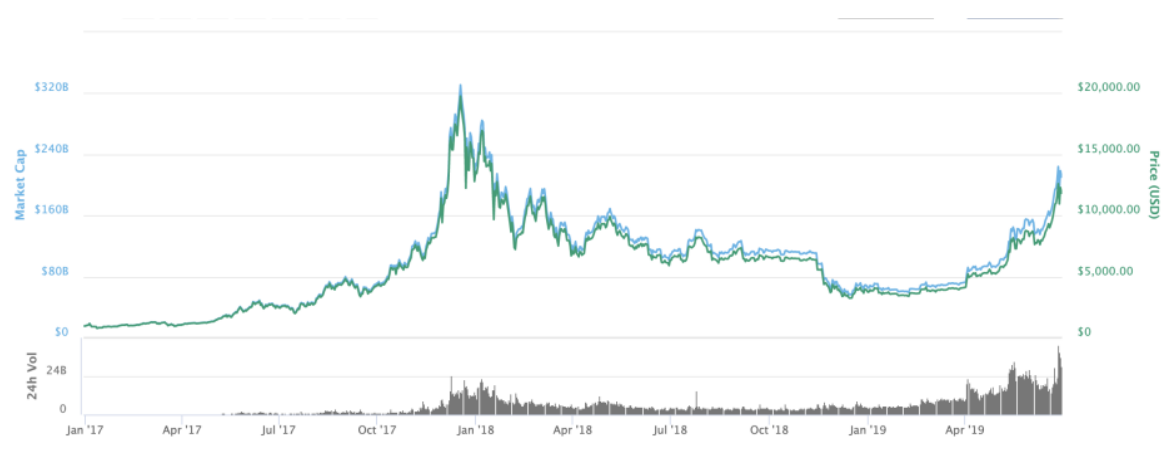

242. Michael Lind, Financial Bubbles and Technological Innovations, PRIV. DeBT PROJECT, https://www.privatedebtproject.org/view-articles.php?Financial-Bubbles-and -Technological-Innovations-33 [https://perma.cc/2EDY-5JY6].

243. Top 100 Cryptocurrencies by Market Capitalization, supra note 236. Through the first half of 2019, bitcoin's price has substantially rebounded from its 2018 lows. 
Explanations for bitcoin's bubble in late 2017 and 2018 are elusive. One potential explanation is that early adopters of the cryptocurrency, known as bitcoin "whales," have an outsized influence over the price of bitcoin. ${ }^{24}$ The lack of market regulation in the bitcoin market enables powerful groups of traders to inject large quantities of bitcoin into the open market, increasing the available supply, and putting downward pressure on the price of bitcoin. Some have speculated that the advent of bitcoin futures in early 2018 led to "massive market manipulation and suppression" by bitcoin whales. ${ }^{245}$

While this might seem like an insurmountable dilemma, bitcoin's ability to compete among all currencies, rather than say just the U.S. dollar, offers it a significant advantage. Additionally, as the market continues to mature, the impact of this overhang of individuals with outsized positions in the bitcoin market should diminish as they continue to diversify their assets and exit from their early adopter positions. Indeed, some have pointed out that the introduction of a bitcoin ETF in the United States could help ease the negative impacts of market manipulation. ${ }^{246}$

This Section previously explored bitcoin's ability to serve those in monetarily oppressive regimes and underbanked. As bitcoin gains adoption among those with inferior alternatives, that adoption will also help stabilize its prices and will help spur its use against alternatives that are now better. In Part IV, we outline some benchmarks for bitcoin's progress. ${ }^{247}$

\section{Bitcoin's Deflationary Model}

Central banks are supposed to keep a stable currency by issuing money at rates that match the goods and services exchanged in an economy. For instance, in the United States, the Fed increases the money supply. ${ }^{248}$ For bitcoin, there is no central authority that can regulate the money base. ${ }^{249}$ Instead the bitcoin algorithm defines, in advance, how currency is created and at what rate. ${ }^{250}$

Bitcoin's inability to match the amount of its currency with the growth of goods and services could lead to deflation and represents a common criticism of this innovation. It has been said that runaway deflation can eventually lead to substantial

244. Anthony Cuthbertson, Bitcoin Price Crash: 'Manipulative Whales' Cause Cryptocurrency Market Meltdown, INDEP. (Sept. 6, 2018, 4:22 PM), https://www.independent.co.uk/life-style/gadgets-and-tech/news/bitcoin-price-crash-whales -cryptocurrency-market-explained-analysis-a8525761.html [https://perma.cc/9MBN-ZHG6].

245. Id.

246. Luke Graham, How Bitcoin Could Overcome Its Wild Reputation, CNBC (Sept. 21, 2017, 7:45 AM), https://www.cnbc.com/2017/09/21/bitcoin-volatility-how-digital-currency -can-overcome-wild-reputation.html?view=story [https://perma.cc/BQ7P-MTV8].

247. See infra Part IV.

248. Ashton S. Phillips, Bank-Created Money, Money Sovereignty, and the Federal Deficit: Toward a New Paradigm in the Government-Spending Debate, 36 W. NEw ENG. L. REV. 221, 236-37 (2014).

249. Jonathan B. Turpin, Bitcoin: The Economic Case for a Global, Virtual Currency Operating in an Unexplored Legal Framework, 21 IND. J. GLOBAL LEGAL STUD. 335, 352 (2014).

250. Controlled Supply, supra note 137; see also Tyler Moore, The Promise and Perils of Digital Currencies, 6 InT'L J. CRITICAL InFRASTRUCture Protection 147 (2013). 
damage to an economy given certain conditions and constraints. ${ }^{251}$ For instance, it is feared that companies and people may defer investments and spending because their holdings will go up in value along with the currency. ${ }^{252}$

This is a large and speculative issue which this Article does not have adequate space to address. It is large because it addresses fundamental issues of monetary theory. It is speculative because unless bitcoin becomes dominant and the unit of account in a nation, it is unlikely to create these problems because transactions will be carried out in other currency. Nevertheless, it is worth noting very briefly three possible responses to this criticism.

First, some recent research has challenged the historical account of deflation as a destabilizing force. ${ }^{253}$ Since World War II, there has been more than 100 years of short-term deflation across thirty-eight economies. ${ }^{254}$ The average growth rate during those periods was found to be higher than those found during periods of normal inflation. ${ }^{255}$ This research raises questions about the prevailing view that price deflation in goods and services, even if persistent, is pernicious.

Second, while historical debate regarding the effects of deflation continues, ${ }^{256}$ there is even greater reason to think that bitcoin deflation will not harm users of the currency. Deflation has historically been unexpected, ${ }^{257}$ but in a bitcoin world, everyone would anticipate deflation, given the fixed supply of bitcoin, and know that what they were getting paid would have greater purchasing power. ${ }^{258}$ This type of predictability simply is not possible in a system of central banking, or in systems of private note issue, due to the inability of such systems to bind themselves to future behavior. ${ }^{259}$

Third, there is yet a more fundamental reason that criticism of bitcoin's deflationary model may prove irrelevant. Even if it were true that the societal worries about deflation are economically harmful, individuals will act in their own interest when deciding to hold bitcoin. While the deflationary spiral may alarm policy makers, individuals may find it in their own best interests to hold a currency that

251. Reuben Grinberg, Bitcoin: An Innovative Alternative Digital Currency, 4 HaSTINGS SCI. \& TECH. L.J. 159, 177 \& n.76 (2012).

252. Beat Weber, Bitcoin and the Legitimacy Crisis of Money, 40 CAMBRIDGE J. ECON. 17, 32-33 (2016).

253. Claudio Borio, Magdalena Erdem, Andrew Filardo \& Boris Hofmann, The Costs of Deflations: A Historical Perspective, BIS Q. REv., Mar. 2015, at 31.

254. Id. at 34-35.

255. Id. at 36 .

256. Simon Kennedy, Central Bankers Fire Back at Their Own Club over Bubbles, BLOOMBERG (July 4, 2014, 5:36 AM), http://www.bloomberg.com/news/articles/2014-07 -04/central-bankers-fire-back-at-their-own-club-over-bubbles [https://perma.cc/9QHQ -MLNY].

257. Tom Simonite, What Bitcoin Is, and Why It Matters, MIT TeCH. ReV. (May 25, 2011), https://www.technologyreview.com/s/424091/what-bitcoin-is-and-why-it-matters [https:// perma.cc/5CFJ-WDDF].

258. Id.; see also Wences Cesares on Bitcoin and Xapo, LIBRARY ECON. \& LIBERTY (July 20, 2015), http://www.econtalk.org/archives/2015/07/wences_casares.html [https://perma.cc /R8WR-UYPC].

259. See supra note 162. 
increases in value in a predictable manner, rather than one that is open to the vagaries of central bank decision-making.

\section{Bitcoin's Energy Consumption}

As bitcoin's market adoption and price have soared to unprecedented levels, a new critique has emerged as the competition among miners to acquire newly minted bitcoin has attracted attention and resources. As bitcoin mining demands the consumption of energy, and that consumption scales almost linearly with the amount of computational resources being spent, many are now claiming that bitcoin use presents a serious global warming problem, and that the problem is only getting worse. ${ }^{260}$

The statistics themselves do paint an alarming picture. Every bitcoin transaction now costs the same amount of energy as it takes to run a household for over a week. ${ }^{261}$ Worldwide, bitcoin mining consumes more electricity than the entire country of Serbia. ${ }^{262}$ By one person's calculations, bitcoin will require more electricity than the United States by July 2019, and by November 2020, it will consume more electricity than the entire world does today. ${ }^{263}$

However, bitcoin mining may not be as environmentally unsustainable as certain critics have claimed. The environmental impact of mining gold is still far costlier than mining bitcoin. Annually, gold mining still consumes over eighteen times more electricity than bitcoin mining. ${ }^{264}$ But more importantly, bitcoin mining is geographically independent. ${ }^{265}$ That is, unlike gold mining, which requires energy consumption at the source of the physical mine, the task of mining for bitcoin can be performed anywhere on the planet.

Why is this important? It means that miners can establish their enterprises in areas with cheap electricity. In fact, most bitcoin mining today happens in the Sichuan

260. See Andrew Griffin, Bitcoin Price Surge Could Be Ruining the Environment Because It Uses So Much Energy, INDEP. (Dec. 6, 2017, 10:18 AM), http://www.independent .co.uk/life-style/gadgets-and-tech/news/bitcoin-environment-green-energy-power-global -warming-climate-change-a8094661.html [https://perma.cc/5SXT-NYV6]; Christopher Malmo, One Bitcoin Transaction Consumes as Much Energy as Your House Uses in a Week, Vice: MotherboARD (Nov. 1, 2017, 3:20 PM), https://motherboard.vice.com/en_us /article/ywbbpm/bitcoin-mining-electricity-consumption-ethereum-energy-climate-change [https://perma.cc/UY2Q-G54B]; Adam Rogers, The Hard Math Behind Bitcoin's Global Warming Problem, WIRED (Dec. 15, 2017, 7:00 AM), https://www.wired.com/story/bitcoin -global-warming/?mbid=social_fb [https://perma.cc/VK6F-W59G].

261. Griffin, supra note 260.

262. Rogers, supra note 260.

263. Id.

264. BITCOIN vs. GOLD: Which One's a Bubble and How Much Energy Do They Really Consume, SRSROCCO REP. (Nov. 1, 2017), https://srsroccoreport.com/bitcoin-vs-gold-whichones-a-bubble-how-much-energy-do-they-really-consume [https://perma.cc/Y4K5-NRCS].

265. Jessica Sier, Andreas Antonopoulos on How Bitcoin Is 'Absolutely a Bubble' and What's Next, AustL. FIN. REV. (Dec. 21, 2017, 11:00 PM), http://www.afr.com /technology/bitcoin-and-the-power-of-decentralisation-20171211-h02i0z [https://perma.cc /MJ7F-HRYR]. In this article, Andreas M. Antonopoulos, a highly regarded bitcoin scholar, is interviewed on a variety of topics concerning bitcoin. 
Province of China. ${ }^{266}$ Sichuan is uniquely situated in that the region produces much more hydroelectric power than it can use. ${ }^{267}$ Similar to many energy projects in developing regions, Sichuan's power plants were planned to meet electrical consumption demand fifty years from now. However, unlike oil and coal production, the amount of hydroelectric power produced by a given water source cannot be controlled, meaning that eighty-five percent of power currently generated in Sichuan is left unused, providing bitcoin miners an opportunity to generate profit while not impacting the environment. ${ }^{268}$

Thus, bitcoin's geographic independence has certain synergies with the economic costs required to build a renewable energy infrastructure. ${ }^{269}$ Unlike oil, renewable energy sources like wind, solar, and hydro are not easily stored, and as such, the excess amount of energy they generate can be allocated to mining for bitcoin without leaving a carbon footprint. ${ }^{270}$ This can enable capital expenditures for renewable energy plants to be more quickly amortized, which may stoke greater investment in infrastructure for a green economy. ${ }^{271}$

\section{BENCHMARKS FOR BITCOIN's PRESENT AND FUTURE}

In this Part, we offer benchmarks for determining how bitcoin compares to other payment mechanisms and currencies. Our analysis provides a framework for analysis of the degree to which bitcoin will turn its potential into success as a currency.

\section{A. Currency Rungs-A Framework for Analyzing Bitcoin's Growth as a Currency}

So far, this Article has explored bitcoin first as a fundamentally new regime of currency operating outside traditional legal mechanisms and then by examining the pros and cons of this regime. This Section offers a more specific framework for analyzing bitcoin's growth and suitability as a currency by introducing the concept of a "currency rung." A currency rung is a way to group different currencies by measuring (1) volatility over time and (2) its growth (or decline) in value as measured against other currencies.

For a currency with a fixed supply, like bitcoin, these two forces may sometimes be at tension - although rampant speculation may drive up a currency's value, the inherent volatility that comes along with such upward swings can be destabilizing for a currency. ${ }^{272}$ However, this tension is not a fatal flaw. If bitcoin maintains a slow, but steady, growth in demand, it will be able to maintain an acceptable level of

266. Id.

267. $I d$.

268. Id.

269. Id.

270. See id.

271. See id.

272. In 2013, bitcoin's value grew from $\$ 12$ to an all-time high of $\$ 1200$, driven largely by rapid introduction to the masses through mainstream media. See Kitco News, 2013: Year of the Bitcoin, ForBES (Dec. 10, 2013, 2:34 PM), http://www.forbes.com/sites/kitconews /2013/12/10/2013-year-of-the-bitcoin/\#6b8f981d2295 [https://perma.cc/SZ7J-YR3N]. 
volatility while at the same time reaching a broader market. This opportunity for growth and lower volatility is propelled by the governments who manipulate their own currencies and thus lose the confidence of their citizenry. As shown in Figure 6, bitcoin's price has continued to climb while its relative volatility dampens.

\section{FIGURE 6. BITCOIN PRICE AND VOLATILITY CHART}

(AUG. 16, 2010-JUN. 28, 2019) $)^{273}$

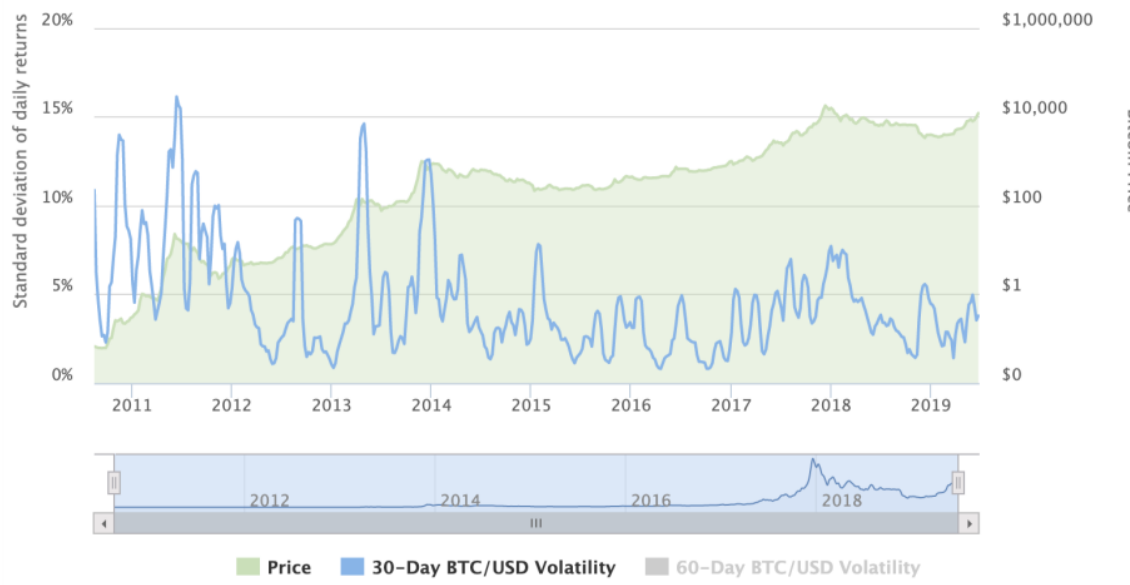

As explained in Section III.B.4, there have been periods where speculation in bitcoin has driven its volatility upwards, which of course reduces its usefulness as a currency. While these periods of speculation create winners and losers in bitcoin trading markets, ${ }^{274}$ bitcoin's ten-plus year history demonstrates that it can survive these growing pains as it matures into a usable currency. Indeed, as Figure 6 demonstrates, volatility during the speculative cycles of late 2017 and 2018 was much lower than volatility during earlier periods of speculation such as late 2013 and early 2014.

As more individuals enter bitcoin markets, we will likely see more and more established institutions participating in a bitcoin ecosystem. Already there are many more exchanges and wallets holding bitcoins. In late 2017, two exchanges offered futures markets on bitcoin. ${ }^{275}$ By offering a hedge against future price changes in bitcoin, these futures markets may expand the users of bitcoin and reduce

273. The Bitcoin Volatility Index, BuY BITCOIN WORLDWIDE, https://btcvol.info [https://perma.cc/MC4D-LKR5].

274. Katie Martin, The Bitcoin Bubble's Real Losers, Fin. TIMES (Aug. 23, 2018), https://www.ft.com/content/c3a8fc74-a600-11e8-926a-7342fe5e173f [https://perma.cc /LH3A-5RV7].

275. Samantha Bomkamp, CBOE, CME to Jump into Bitcoin Trading, CHI. TRIB. (Dec. 1, 2017, 6:50 PM), http://www.chicagotribune.com/business/ct-biz-cboe-cme-bitcoin -20171201-story.html [https://perma.cc/YF8Q-8GKZ]. 
volatility. ${ }^{276}$ Thus, while it is far from a certainty, bitcoin's qualitative advantages over fiat may allow it to climb currency rungs and compete with many currencies on a global scale.

\section{First Tier: Bitcoin vs. Reserve Currencies}

Currencies that instill sufficient confidence that they are widely held outside of their nation are called reserve currencies. ${ }^{277}$ Briefly, foreign individuals and foreign institutions hold these currencies because their relatively low volatility and good prospects of holding their value makes them function well both as stores of value and as mechanisms to facilitate economic transactions, particularly foreign exchange and trade. ${ }^{278}$ Reserve currencies thus are the top tiers of all currencies.

It is important to recognize that although reserve currencies are more stable than others, over time some currencies can lose that status and others can gain it. Prior to World War I, the pound was the reserve currency. ${ }^{279}$ However, as explored in Part I, a government's ability to isolate its currency from the pressures of politics is limited. After the war, the pound lost its status to the dollar, for a variety of reasons, including the relative independence of the Fed over the Bank of England. ${ }^{280}$

By its structure, bitcoin has some potential advantages even over reserve currencies because it is not dependent on any government. Unlike bitcoin's community of miners, governments have objectives other than preserving and enhancing the value of the currency and have historically pursued these objectives. Nonetheless, bitcoin is in its infancy and still far from competing directly with reserve currencies because of its substantially greater volatility.

Despite its infancy and relative lack of appeal as a store of value against other reserve currencies, bitcoin's qualitative features could potentially allow it to one day compete against state-issued fiat. Its underlying technology allows international transactions to be completed in seconds, making it useful in foreign exchange and trade. Additionally, bitcoin is a currency without political allegiance, which may make it attractive to nations who, for political reasons, may not wish to support another nation by driving up demand for its currency.

Even if bitcoin becomes a reserve currency, it is doubtful that governments will simply give up printing their own currencies, but instead they will compete against bitcoin to offer superior forms of fiat than are currently available. Even today, central banks are exploring the idea of offering competing digital currencies. Recently, the Bank of England released a white paper where it explored the potential to replace the

276. Philip Stafford, US Regulator Gives Green Lights for Bitcoin Futures Trading, FIN. TIMES (Dec. 1, 2017), https://www.ft.com/content/43d69af8-d6b0-11e7-8c9a-d9c0a5c8d5c9 [https://perma.cc/J6CX-M76D].

277. See Alan S. Blinder, The Role of the Dollar as an International Currency, 22 E. ECON. J. 127 (1996); Gabriele Galati \& Philip Wooldridge, The Euro as a Reserve Currency: A Challenge to the Pre-eminence of the US Dollar?, 14 INT'L J. FIN. \& ECON. 1, 2 (2009).

278. Galati \& Wooldridge, supra note 277, at 3.

279. See Richard J. Herring, Default and the International Role of the Dollar, in Is U.S. GOVERNMENT DEBT DiFFERENT? 21, 26 (2012).

280. Id. 
pound with a "central bank digital currency" (CBDC). ${ }^{281}$ Unlike bitcoin, CBDC would be created whereby a central bank fixes the quantity of CBDC relative to GDP and releases the currency against government bonds. ${ }^{282}$ The Bank of England claims that CBDC would enable individuals to hold and transfer money without requiring a bank via blockchain technology that is similar to that of bitcoin. ${ }^{283}$ Even if successful, order without law in currency is thus not likely to entirely end the law of currency but rather to transform it.

\section{Second Tier: Bitcoin vs. Emerging Market Currencies}

But bitcoin does not need to compete against reserve currencies at first. Bitcoin's best opportunity for maturing as a currency is by competing against nonreserve currencies, particularly in emerging markets. Because of the fragility of the laws respecting currencies in some of these nations, ${ }^{284}$ bitcoin is competing with some of those currencies already. While it is still more volatile than most of these currencies, that gap may be narrowing, ${ }^{285}$ and its appreciating value makes it an attractive option to those who distrust their government's ability to maintain the value of its own currencies. A recent example of this is the explosive increase in the demand of bitcoin in Venezuela during its economic and political crises:

281. John Barrdear \& Michael Kumhof, The Macroeconomics of Central Bank Issued Digital Currencies 7 (Bank of Eng. Staff, Working Paper No. 605, 2016), https:// www.bankofengland.co.uk/-/media/boe/files/working-paper/2016/the-macroeconomics-of -central-bank-issued-digital-currencies.pdf?la=en\&hash=341B602838707E5D6FC26884588 C912A721B1DC1 [https://perma.cc/Q8BA-BBDW].

282. Id. at $17-19$.

283. Id. at 3-6.

284. See supra Section I.B.2.

285. See infra Figure 7. 
FigURE 7. WeEKLY BITCOIN VOLUMES IN THE VENEZUELAN BOLIVAR

(OCT. 12, 2013-JUN. 15, 2019) 286

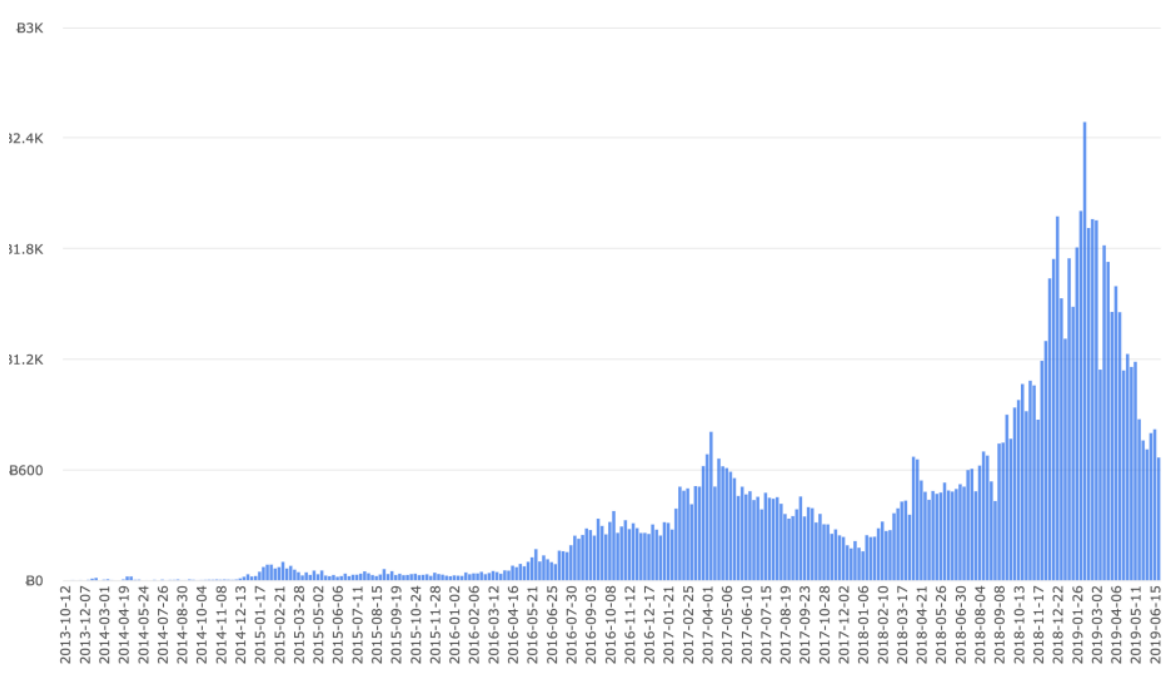

Consider the currencies of three representative and important markets: Brazilian real (BRL), South African rand (ZAR), and Chinese yuan (CNY). First, all three emerging market currencies witnessed a sharp depreciation against the U.S. dollar during the past four years while bitcoin climbed in the same period. Second, with the exception of the speculative period in late 2017 and 2018, the gap in volatility between these currencies and bitcoin has shrunk compared to the early years of bitcoin:

Figure 8. VolatiLity OF BITCOIN VS. EMERGING MARKET CURRENCIES 287

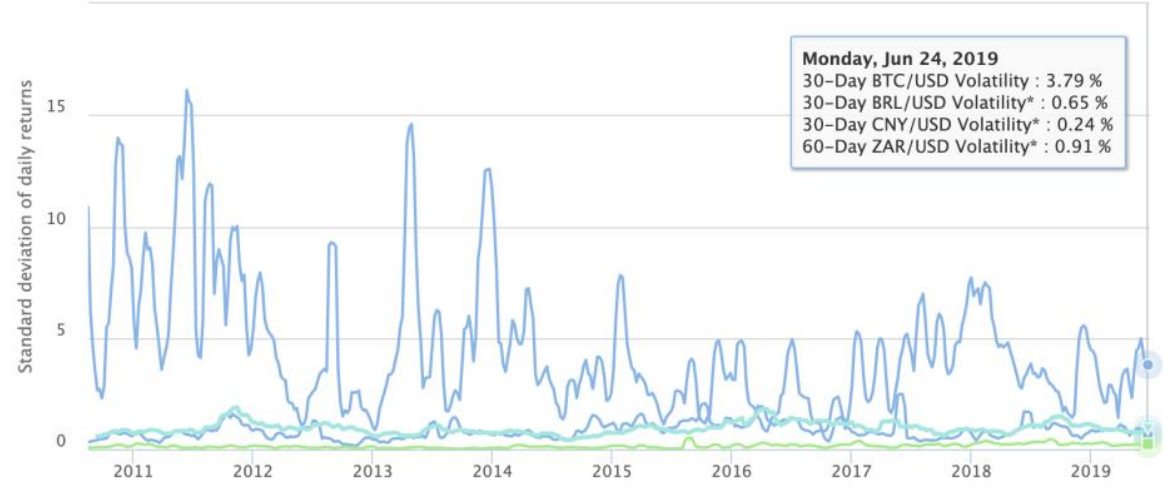

286. LocalBitcoins Volume (Venezuela), COIN DANCE, https://coin.dance/volume /localbitcoins/VES/BTC [https://perma.cc/U928-CDF3].

287. The Bitcoin Volatility Index, supra note 273. 


\section{Third Tier: Bitcoin vs. Gold (The Commodity Tier)}

The third tier of currency is the "Commodity Tier." Historically, currencies in this tier, such as gold and silver, are safe havens that investors flock to during times of financial panic as a substitute for fiat currencies and as a hedge against inflation and/or political uncertainty. Bitcoin and gold share certain similarities. ${ }^{288}$ Both are limited in supply. ${ }^{289}$ Bitcoin and gold both have functional utility: gold is desirable for use in jewelry and electronic circuits, and bitcoin is desirable for its usefulness in exchanging value.

However, despite these similarities, bitcoin has some natural advantages over gold-lower storage costs and greater capacity to function as a payment system. Already, the market for bitcoin has functioned as an alternative to gold as a safe haven investment. ${ }^{290}$ During Cyprus's severe banking crisis, the price of bitcoin doubled within the space of two weeks. ${ }^{291}$ Following the surprising outcome of the United Kingdom's Brexit vote, the price of bitcoin surged, and exchanges offering to exchange bitcoin for the British pound "experienced a substantial increase in user sign ups. ${ }^{292}$

Indeed, while bitcoin's volatility is still more than that of gold, its absolute return has far outpaced the precious metal.

\section{Fourth Tier: Bitcoin vs. Other Cryptocurrencies}

The final tier of currencies we define is cryptocurrencies. A cryptocurrency's value is inherently tied to the ingenuity of the algorithm that produces it and the network of individuals who advocate for it and use it. At its inception, bitcoin was almost valueless - the first recorded bitcoin transaction was the purchase of two pizzas in Jacksonville, Florida, in 2010 for the price of 10,000 bitcoin. ${ }^{293}$ While other

288. Chen Y. Wu \& Vivek K. Pandey, The Value of Bitcoin in Enhancing the Efficiency of an Investor's Portfolio, 27 J. Fin. Plan., Sept. 2014, at 44.

289. Id.

290.

[T] he ability of [b]itcoin to act as a hedge against uncertainty is conditional on not only whether the market is in bear or bull regime but also whether global uncertainty is high or low. Specifically speaking, at shorter investment horizons, [b]itcoin returns seem to hedge against the global uncertainty at extreme ends of both [b]itcoin returns and uncertainty.

Elie Bouri, Does Bitcoin Hedge Global Uncertainty? Evidence from Wavelet-Based Quantilein-Quantile Regressions (U. of Pretoria, Working Paper No. 2016-90, 2016), http://www .up.ac.za/media/shared/61/WP/wp_2016_90.zp105924.pdf [https://perma.cc/GW3X-US8W].

291. Alexander Lielacher, Is Bitcoin a Better 'Safe Haven' than Gold?, BTCMANAGER (Dec. 5, 2016), https://btcmanager.com/is-bitcoin-a-better-safe-haven-than-gold [https:// perma.cc/N49S-C9RG].

292. Id.

293. At today's valuation, the cost of each pizza was roughly $\$ 50,000,000$. Brian Merchant, This Pizza Cost \$750,000, Vice: Motherboard (Mar. 26, 2013, 9:00 AM), https://motherboard.vice.com/en_us/article/yppj8b/this-pizza-is-worth-750000 [https://perma .cc/X7UX-FFH2]. 
cryptocurrencies have emerged, bitcoin has maintained its superiority not only in its overall value, but also in its growth as a more stable store of value.

\section{FigURE 9. MAJOR CRYPTOCURRENCY MARKET CAPITALIZATION \\ (JUN. 29, 2019) 294}

\begin{tabular}{|c|c|c|c|c|c|}
\hline$\#$ & Name & Market Cap & Price & Volume (24h) & Circulating Supply \\
\hline 1 & (B) Bitcoin & $\$ 210,733,624,816$ & $\$ 11,846.90$ & $\$ 30,519,941,186$ & $17,788,075$ ВТС \\
\hline 2 & Ethereum & $\$ 32,797,119,709$ & $\$ 307.40$ & $\$ 10,445,226,959$ & $106,692,986 \mathrm{ETH}$ \\
\hline 3 & $\asymp \mathrm{XRP}$ & $\$ 17,977,201,478$ & $\$ 0.422331$ & $\$ 1,708,562,843$ & $42,566,596,173$ XRP * \\
\hline 4 & (C) Litecoin & $\$ 8,360,006,019$ & $\$ 133.88$ & $\$ 5,481,139,659$ & $62,445,276$ LTC \\
\hline 5 & [৫] Bitcoin Cash & $\$ 7,733,758,925$ & $\$ 432.91$ & $\$ 2,127,776,277$ & $17,864,525 \mathrm{BCH}$ \\
\hline 6 & $\triangle$ EOS & $\$ 5,801,690,684$ & $\$ 6.30$ & $\$ 2,881,345,237$ & $921,149,443$ EOS * \\
\hline
\end{tabular}

Figure 10. AVERAge DaILy Price Movement For ToP Five CRYPTOCURRENCIES ${ }^{295}$

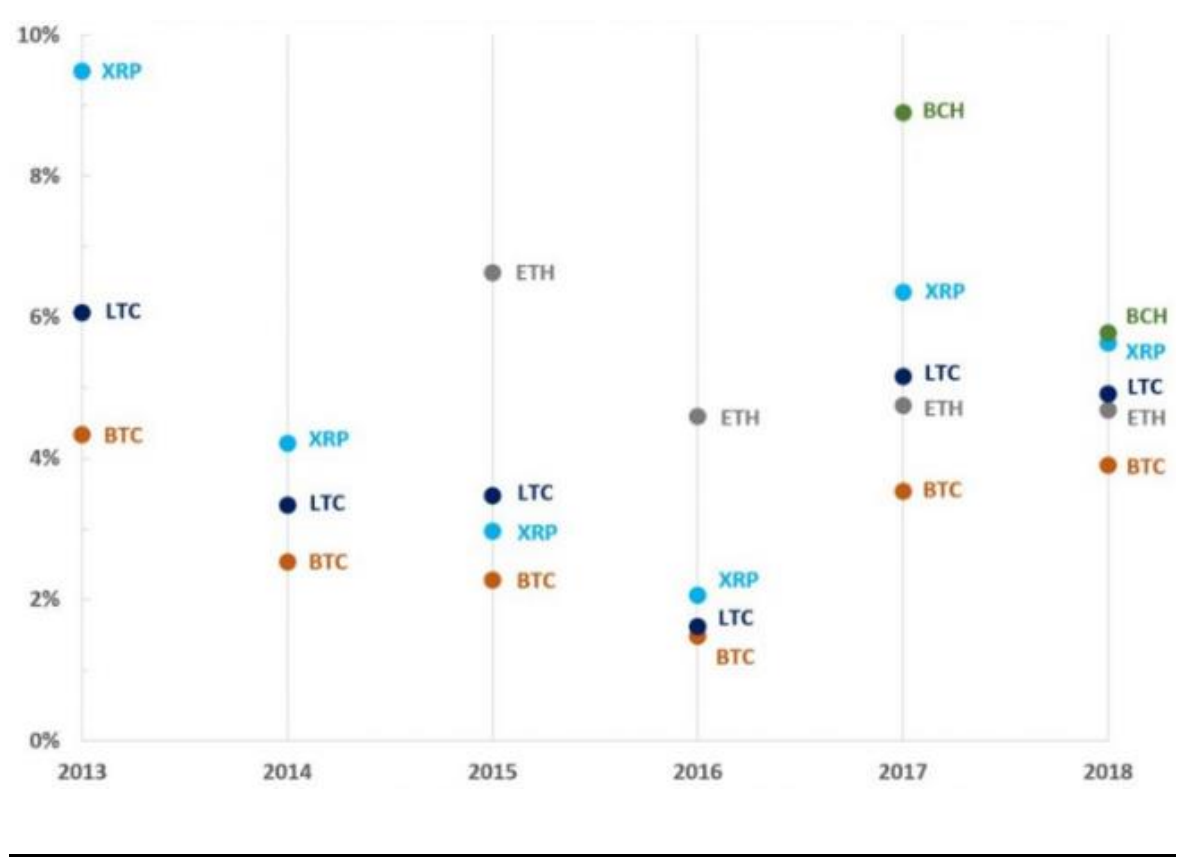

294. Top 100 Cryptocurrencies by Market Capitalization, supra note 236.

295. Safinus, Bitcoin Is Less Volatile than Other Cryptocurrencies, Medium (June 22, 2018), https://medium.com/@safinus.com/bitcoin-is-less-volatile-than-other-crypto 


\section{B. Bitcoin's Path Forward}

Thus, there is already evidence that bitcoin is climbing the rungs to become a more stable store of value. While it is beyond the scope of this Article to give a complete account of the forces helping bitcoin succeed, we can briefly offer three reasons. First, bitcoin has appeared to develop a more diversified participation base. As people from diverse backgrounds enter the market, demand is more likely to match up and real demand to cancel out speculative flows. Price stability results. The advantage of gaining worldwide participants is most apparent in the reserve currencies such as the U.S. dollar, euro, and Japanese yen. The same can be said about bitcoin as it has grown from a toy among a closed circle of geeks to a medium of exchange for a wider public.

Second, bitcoin gains more users hedging against currency shocks in times of political and economic crises-Brexit, the American presidential election, and the refugee crisis to name just three. Central banks often react by easing the money supply to avoid liquidity concerns sparked by such crises. ${ }^{296}$ But monetary easing can raise concerns about inflation. ${ }^{297}$ In short as the political world becomes riskier, bitcoin seems less risky in comparison.

Finally, the passage of time can help bitcoin. Bitcoin was an entirely novel human creation. Only time will tell whether an artifice is viable. Proponents of bitcoin are relieved to see it has survived hacks, scandals, peer group competition, and a general disapproval by governments. The price drop following the Bitfinex scandal in the middle of 2016 was much smaller in magnitude than when Mt. Gox collapsed in $2014 .{ }^{298}$ When a market rumor swirled around in early November of 2016 that the Chinese government was about to regulate bitcoin trading to plug the loopholes in capital outflow, the price drop was almost negligible compared with when China's central bank came close to banning bitcoin in late 2013. ${ }^{299}$ The more resilience

currencies-13224b145e2c [https://perma.cc/3FPP-GH4P]. This data is collected on an annual basis.

296. See, e.g., Michael D. Bordo, Exiting from Low Interest Rates to Normality: An Historical Perspective (Hoover Inst. Econ., Working Paper No. 14110, 2014), https://www.hoover.org/sites/default/files/14110_-_bordo_-_exiting_from_low_interest _rates_to_normality_-_an_historical_perspective.pdf [https://perma.cc/6UJ9-9QB7]; Filippo Occhino, Central Bank Lending in a Liquidity Crisis, Fed. Res. Bank Cleveland (Apr. 13, 2016), https://www.clevelandfed.org/newsroom-and-events/publications/economic -commentary/2016-economic-commentaries/ec-201602-central-bank-lending-in-a-liquidity -crisis.aspx [https://perma.cc/N6R7-LHV4].

297. Daniel L. Thornton, Fed. Res. Bank St. Louis, The Downside of Quantitative EASING (2010), https://files.stlouisfed.org/files/htdocs/publications/es/10/ES1034.pdf [https:// perma.cc/PYT8-DYKP].

298. Immediately following the August 2, 2016, hack on Bitfinex, the price of bitcoin fell roughly twenty percent, and less than two months later, it was trading above the price point pre-hack. See Bitcoin Price, COINDESK, http://www.coindesk.com/price [https:// perma.cc/ZHL3-RMXQ]. By contrast, after Mt. Gox suspended trading following its hack in 2014 , the bitcoin price tumbled nearly seventy percent and did not recover until two years later. $I d$.

299. Id. The USD-to-bitcoin exchange rate went from roughly $\$ 742$ to $\$ 687$ from November 2 to November 3, 2016, a price drop of roughly seven percent. 
bitcoin exhibits in times of crisis, the more faith market participants place in its future. A positive feedback loop is thus entrenched.

\section{CONCLUSION}

Software is eating away even at a function as basic as currency. The digital revolution is evolving from a phenomenon that changed the way we communicate to an era that is producing innovations that disrupt many of our preconceived notions of law and governance. While it is unlikely that any cryptocurrency will dislodge the dollar or other major currency anytime soon, bitcoin's striking growth over the last decade is proof that cryptocurrency has the potential to change the way individuals and societies exchange value. Its ultimate success is not yet assured, and that success likely depends on the ecosystem that grows up to surround it - an ecosystem that itself will depend on government regulation and established private law of property and contract. Nevertheless, bitcoin is significant not only for its own peculiar form of order without currency law, but also for establishing a platform that will help sustain other forms of nonlegal order. 